\title{
Analysis of CTCL cell lines reveals important differences between mycosis fungoides/Sézary syndrome vs. HTLV-1+ leukemic cell lines
}

\author{
Elena Netchiporouk ${ }^{1, *}$, Jennifer Gantchev ${ }^{1, *}$, Matthew Tsang2 ${ }^{2}$ Philippe Thibault ${ }^{3}$, \\ Andrew K. Watters ${ }^{4}$, John-Douglas Matthew Hughes ${ }^{2}$, Feras M. Ghazawi ${ }^{2}$, Anders \\ Woetmann $^{5}$, Niels Ødum ${ }^{5}$, Denis Sasseville ${ }^{1}$ and Ivan V. Litvinov ${ }^{1,2}$ \\ ${ }^{1}$ Division of Dermatology, McGill University, Montréal, Québec, Canada \\ ${ }^{2}$ Division of Dermatology, University of Ottawa, Ottawa, Ontario, Canada \\ ${ }^{3}$ Université de Sherbrooke Rnomics Platform, Sherbrooke, Québec, Canada \\ ${ }^{4}$ Department of Pathology, McGill University Health Centre, Montreal, Québec, Canada \\ ${ }^{5}$ Department of International Health, Immunology, and Microbiology, University of Copenhagen, Copenhagen, Denmark \\ *These authors have contributed equally to this work \\ Correspondence to: Ivan V. Litvinov, email: ivan.litvinov@mcgill.ca \\ Denis Sasseville, email: denis.sasseville@mcgill.ca \\ Keywords: human T-cell lymphotropic virus type 1; cutaneous T-cell lymphomas; spectral karyotyping; gene expression analysis; \\ xenograft tumors \\ Received: July 20, $2017 \quad$ Accepted: August 26, $2017 \quad$ Published: October 07, 2017 \\ Copyright: Netchiporouk et al. This is an open-access article distributed under the terms of the Creative Commons Attribution \\ License 3.0 (CC BY 3.0), which permits unrestricted use, distribution, and reproduction in any medium, provided the original author \\ and source are credited.
}

\section{ABSTRACT}

HTLV-1 is estimated to affect $\sim 20$ million people worldwide and in $5 \%$ of carriers it produces Adult T-Cell Leukemia/Lymphoma (ATLL), which can often masquerade and present with classic erythematous pruritic patches and plaques that are typically seen in Mycosis Fungoides (MF) and Sézary Syndrome (SS), the most recognized variants of Cutaneous T-Cell Lymphomas (CTCL). For many years the role of HTLV1 in the pathogenesis of MF/SS has been hotly debated. In this study we analyzed CTCL vs. HTLV-1+ leukemic cells. We performed G-banding/spectral karyotyping, extensive gene expression analysis, TP53 sequencing in the 11 patient-derived $H T L V-$ $1^{+}$(MJ and Hut102) vs. HTLV-1- (Myla, Mac2a, PB2B, HH, H9, Hut78, SZ4, Sez4 and SeAx) CTCL cell lines. We further tested drug sensitivities to commonly used CTCL therapies and studied the ability of these cells to produce subcutaneous xenograft tumors in NOD.Cg-Prkdc ${ }^{\text {scid }} \mathrm{II}_{2} \mathrm{rg}^{\text {tm1 } 1 \mathrm{wil}} / \mathrm{SzJ}$ mice. Our work demonstrates that unlike classic advanced MF/SS cells that acquire many ongoing balanced and unbalanced chromosomal translocations, $H T L V-1^{+}$CTCL leukemia cells are diploid and exhibit only a minimal number of non-specific chromosomal alterations. Our results indicate that $H T L V-1$ virus is likely not involved in the pathogenesis of classic MF/SS since it drives a very different pathway of lymphomagenesis based on our findings in these cells. This study also provides for the first time a comprehensive characterization of the CTCL cells with respect to gene expression profiling, TP53 mutation status, ability to produce tumors in mice and response to commonly used therapies. 


\section{INTRODUCTION}

Viruses are known to cause a number of human cancers, where Human Papilloma Virus (HPV), Human Herpesvirus 8 (HHV8) and Merkel Cell Polyomavirus were shown to cause Squamous Cell, Kaposi Sarcomas and Merkel Cell cancers, respectively. Similarly, EpsteinBarr Virus (EBV) and Human T-Cell Lymphotropic Virus Type $1(H T L V-1)$ were implicated as causes for a number of hematologic malignancies [1-3], where specifically $H T L V-1$ is known to cause Adult T-Cell Leukemia/ Lymphoma (ATLL), a WHO recognized variant of Cutaneous T-Cell Lymphoma (CTCL) $[4,5]$. It is estimated that $\sim 20$ million people are infected with $H T L V-1$ around the world. This virus is prevalent in Central and West Africa, in the Caribbean, in Central and South America, in native populations in Canada, and among intravenous drug users in the United States [6].

Cutaneous T-Cell Lymphoma (CTCL) is the most common lymphoma of the skin [7]. Most CTCL variants (with a notable exception of ATLL and Extranodal NK/Tcell lymphoma, nasal type) are not caused by an HTLV-1 or another virus. CTCL was reported to be more common in $\mathrm{HIV}^{+}$individuals [7-9]. Mycosis Fungoides (MF), its leukemic form, Sézary Syndrome (SS), and primary cutaneous anaplastic large cell lymphoma (cALCL) are the most common forms and account for $\sim 80 \%$ of all CTCL [10].

MF typically presents with erythematous patches and plaques on the trunk following a bathing suit distribution, but as the disease progresses skin involvement can become confluent and patients can develop erythrodermic disease. MF can involve skin, lymph nodes, blood, bone marrow and visceral organs. SS is characterized by a triad of erythroderma, lymphadenopathy and detection of malignant $T$ cells with cerebriform nuclei on a peripheral blood smear [5].

Before, SS was viewed as being on the same continuum with MF and was mostly regarded as an aggressive leukemic form of MF. However, as highlighted recently, SS is now considered separate from MF and erythrodermic/leukemic MF [11]. SS typically arises de novo and evolves in a short time period, although some patients may have a prodrome of pruritus, erythema and nonspecific dermatitis $[11,12]$. It also has a much worse overall prognosis than the leukemic MF. In Caucasians $\mathrm{MF} / \mathrm{SS}$ primarily affect individuals over 55 years of age, while in African-Americans, Hispanics and Arabic individuals this disease presents at a significantly younger age [13-15].

$H T L V-1$ in $\sim 5 \%$ of carriers produces ATLL, which can have variable presentations and can often masquerade and present with classic MF-like erythematous pruritic patches and plaques. This can lead to misdiagnosis of Mycosis Fungoides. In fact, in two high profile reports published in Science and PNAS journals, two patients (a 50 year-old Caucasian male form Boston, MA and a 28 yearold African-American male presenting to the National Cancer Institute Veterans Administration hospital in Bethesda, MD) were diagnosed with "advanced Mycosis Fungoides" and have provided critical samples to establish MJ and Hut102 CTCL cell lines, respectively. These cell lines were later found to harbor $H T L V-1$ virus and, hence likely represent ATLL, not Mycosis Fungoides. Despite that, on the American Tissue Culture Collection (ATCC) website MJ is listed as "Cutaneous T Cell Lymphoma; Mycosis Fungoides" cell line and Hut102 is listed as "Lymphoma; Mycosis Fungoides" and not ATLL cell line. $H T L V-1$ serologic screening plays a key role to establish the diagnosis of ATLL in patients and without this test distinguishing the two lymphomas in North America would be very challenging in the clinic. To further complicate these matters, MF can exhibit an identical clinical course as the smoldering, chronic, lymphoma and leukemic variants of ATLL.

Distinguishing these lymphomas and better understanding their biologic differences is not of mere academic interest since ATLL poses a much greater risk to patients than MF, and may require earlier initiation of multimodality chemotherapy treatments and/or bone marrow stem cell transplantation. In addition, even in healthy $H T L V-1$ carriers impaired immune responses against $E B V$ have been observed [16]. One way the virus leads to immunodeficiency is by infecting $\mathrm{CD} 8^{+}$ T-lymphocytes, which impairs their function [17]. At last, it is important to distinguish these cancers to appropriately council our patients about precautions to decrease the risk of HTLV-1 transmission. Hence, it is critical to better understand the fundamental differences between $H T L V-1^{+}$ vs. HTLV-1' lymphomas/leukemias. The current study was designed to highlight key molecular differences between classic MF/SS disease and $H T L V-1^{+}$leukemias.

\section{RESULTS}

Patient-derived cells are indispensable and are routinely used as robust and reproducible models to study human cancers. For CTCL, in particular, 11 patientderived cell lines are available to study this malignancy [18-20]. As discussed in the introduction, two of the cell lines (MJ and Hut102) harbor HTLV-1 virus. Furthermore, these cell lines remain poorly characterized and it remains not well elucidated which cell lines represent Mycosis Fungoides vs. Sézary Syndrome variants of CTCL. First and foremost, we have reviewed the original publications describing these cell lines. A summary of data from these papers is presented in Supplementary Table 1 and in Supplementary Materials of this report. Based on the available description of these patients, it appears that MyLa cells represent advanced extensive Mycosis Fungoides skin disease, Mac2A and PB2B lines represent advanced $\mathrm{CD} 30^{+}$lymphoproliferative skin lymphoma, $\mathrm{HH}$ 
cells represent aggressive leukemic MF, while SZ4/Sez4, Hut78/H9 and SeAx cells represent Sézary Syndrome. Notably, as discussed above, Hut102 and MJ cells were indicated to represent Mycosis Fungoides, but were found to have $H T L V-1$ virus.

\section{Use of RT-PCR assay to detect HTLV-1 virus in patient-derived cell lines}

First and foremost, we used the previously described RT-PCR assay that is based on the detection of expression of Tax, Gag, Pol, Env and $p X$ genes to identify which cells harbor $H T L V-1$ virus [21, 22]. This analysis demonstrated that out of 11 tested cell lines only MJ and Hut102 cells expressed these genes and are infected by HTLV-1 (Supplementary Figure 1). Importantly, this assay confirmed that Myla, Mac2a, PB2B, HH, H9, Hut78, SZ4, Sez4 and SeAx cells are HTLV-1 negative.

\section{Structural karyotype analysis of the 11 patient- derived cell lines}

A number of important chromosomal alterations were reported in MF and SS patients with a number of important differences documented between MF and SS [23-28]. Hence, we wanted to perform G-band analysis and spectral karyotyping in our panel of CTCL cell lines. For each cell line we analyzed five cells by spectral karyotyping. This analysis revealed that all CTCL cell lines except the HTLV-1+ $\mathrm{MJ}$ and Hut102 cells demonstrate significant and ongoing genomic instability, where multiple different chromosomal changes are observed between these five cells within the same cell line. Summary of all karyotype data is presented in Table 1, while detailed karyotype findings are presented in Supplementary Tables 2-3.

As alluded to above, one striking observation was that MyLa, PB2B, Mac2A, HH, Hut78, H9, SeAx, Sez4 and SZ4 cells are mostly aneuploid and have a large number of alterations, while Hut102 and MJ HTLV $-1^{+}$ cells are mostly diploid and have very few structural alterations. This dramatic difference highlights that even though MJ and Hut102 cells were derived from the "so called" MF CTCL patients they are vastly different form the classic MF/SS disease as represented by the other 9 patient-derived cell lines. Indeed, previous reports did indicate a paucity of chromosomal alterations in ATLL patients [29, 30]

Next, based on this analysis we wanted to identify chromosomal abnormalities that are common for a given cell line and, more importantly, determine chromosomal alterations that are seen across multiple cell lines. These findings are presented in Supplementary Tables 2-3. These results demonstrate that, as expected, H9 and Hut78 (H9 is a clonal line derived from Hut78) are almost identical structurally based on the number of shared chromosomal aberrations. Similarly, PB2B and Mac2A have a very similar number and types of chromosomal aberrations, which highlights that they represent the same clinical disease, but at different time points, as indicated in the original report $[31,32]$. Notably, this analysis further confirms that, indeed, these biopsied skin tumors in this patient were caused by the same $\mathrm{T}$ cell clone [31, 32]. Also, our karyotype analysis confirms that SZ4 and Sez4 are essentially the same cell line that at some point acquired different names (Supplementary Tables 2-3).

\section{Karyotype comparison of cell lines and human patient data}

As demonstrated by the above analysis, 9 patient derived MF/SS cell lines have numerous chromosomal abnormalities and exhibit ongoing genomic instability, as highlighted by many changes that are seen sporadically in different cells within the same cell line (Table 1). In contrast, this was not seen in MJ and Hut102 HTLV-1 ${ }^{+}$ cells. One question emerges is whether these structural findings reflect the clinical disease that is observed in $\mathrm{MF} / \mathrm{SS}$ patients? Furthermore, it is recognized that certain structural chromosomal aberrations are more common in MF than SS. Can the presence or absence of these chromosomal aberrations help define cell lines as being representative of MF skin, lymph node vs. SS blood/ leukemic disease?

To answer these questions we compared our karyotype cell line findings to karyotype analysis of patients that were described in 15 seminal manuscripts [23-27, 33-42]. The number of selected papers is not exhaustive, but provides a broad representation of karyotype anomalies seen in MF and SS patients. Our detailed findings are presented in Supplementary Table 4. From this analysis it is evident that, like patient-derived cell lines, MF and SS patients universally exhibit a great number of chromosomal gains, losses, balanced and unbalanced translocations and other structural aberrations. This analysis demonstrates striking disease heterogeneity, where only few chromosomal alterations were noted across multiple studies (e.g., loss of 10q24, 9p21 etc.), while most chromosomal alteration are only reported to occur sporadically [23-28].

Notably, every time an aberration was seen in $\mathrm{MF}$ / SS patients, aberrations in the same regions were also observed in the studied patient-derived cells. Importantly, chromosomal losses in 1p36.1, 9p21, 13q14 and 16q24 regions that were commonly seen in MF and SS patients were also present in 2-5 out of 11 studied CTCL cell lines (Supplementary Table 4). Interestingly, losses and gains that were seen in 10q24 region in SS patients were also observed in blood-derived SeAx, Sez4, SZ4, H9, Hut78 and $\mathrm{HH}$ cells, but not in skin-derived MF MyLa, Mac2A and PB2B cells. Hence, loss of 10q24 region could be a structural change marker indicative of a leukemic disease. 
Table 1: Results of $\mathrm{G}$ band and spectral karyotyping analyses for the 11 patient-derived CTCL cell lines

Cell line G to Sky karyotype findings

46 48,XY,der(1)(1pter $\rightarrow 1 \mathrm{q} 32:)[5], \operatorname{der}(1) \mathrm{t}(1 ; 15)(\mathrm{p} 36.2 \sim 36.3 ; \mathrm{q} 15)[5], \operatorname{der}(2) \mathrm{t}(2 ; 14)$

$(\mathrm{q} 32 \sim 33 ; \mathrm{q} 12 \sim 13)[5], \mathrm{t}(4 ; 5)(\mathrm{q} 13 ; \mathrm{q} 14)[5], \operatorname{der}(5) \mathrm{t}(5 ; ?)(\mathrm{q} 35 ; ?)[5], \operatorname{del}(6)(\mathrm{q} 15 \mathrm{q} 23)[5], \operatorname{del}(7)(\mathrm{p} 15)$

[5],del(9)(p21)[5],der(10)t(10;13)(p14;q13)[5], der(13)t(13;14)(q33;q21)[5],der(13)t (13;16)

MyLa

$(\mathrm{q} 14 ; ? \mathrm{q} 23)[5], \operatorname{der}(14)(2 \mathrm{pter} \rightarrow 2 \mathrm{p} 13:: 14 \mathrm{p} 12 \rightarrow 14 \mathrm{q} 12 \sim 13:: 2 \mathrm{q} 32 \sim 33 \rightarrow 2 \mathrm{qter})[5]$, der(14)t(14;18)

(q22;q22)[4], der(15)t(1;15)(q32;q15)[5],+17 [5], der(18)t(18;?19)(q23;p13.1 13.2)[5],der(19)

$\mathrm{t}(? 11 ; 19)(? ; \mathrm{p} 13.1 \sim 13.2)[5], \operatorname{der}(20) \mathrm{t}(20 ; ?)(\mathrm{q} 13.3 ; ?)[5], \operatorname{der}(21) \mathrm{t}(20 ; 21)(? \mathrm{p} 11.2 ; \mathrm{q} 22.3)[5], ? \mathrm{psu}$

$\operatorname{dic}(16 ; 22)(\mathrm{p} 10 ; \mathrm{p} 13)[5][\mathrm{cp} 5]$

43 44,X,-Y [5],t(3;7)(q22 23;q21.2 22)[5],del(6)(q15)[5], der(6)t(6;22)(p21.1 21.2;q11.1)

$[5], \operatorname{der}(8)(? 9 ? \rightarrow ? 9 ?:: 8 \mathrm{p} 22 \rightarrow 8 \mathrm{qter})[5], \operatorname{der}(9)(8 \mathrm{pter} \rightarrow 8 \mathrm{p} 22:: 9 \mathrm{p} 24 \rightarrow 9 \mathrm{q} 34:: ? 5 ? \rightarrow ? 5 ?)[4], \operatorname{der}(10)$

$($ acro-p::10q10 $\rightarrow$ 10qter)[5],der(10)(10pter $\rightarrow 10 q 2 ? 6:: 10 q 2 ? 6 \rightarrow 10 q 2$ ? $:: 12 q 21 \rightarrow 12 q$ ter)[5],

Mac2A $\operatorname{der}(11) \mathrm{t}(11 ; 14)(\mathrm{q} 22 ; \mathrm{q} 13 \sim 21)[5], \operatorname{del}(12)(\mathrm{q} 11 \mathrm{q} 13)[5],-14$ [5], $\operatorname{der}(15) \mathrm{t}(2 ; 15)(\mathrm{p} 11.2 ; \mathrm{p} 12)[5], \operatorname{del}(16)$ $(\mathrm{q} 11.2 \mathrm{q} 22)[5], ? \operatorname{dup}(16)(\mathrm{q} 21 \mathrm{q} 24)[5], \operatorname{der}(20)(: 20 ? \mathrm{q} 13.1 \rightarrow 20 ? \mathrm{q} 13.1:: 20 \mathrm{p} 13 \rightarrow 20 \mathrm{q} ? 13.1:: 20 \mathrm{q} ? 13$. $1 \rightarrow 20 q$ ter $)[5],-22$ [5],der(22)(6?pter $\rightarrow 6$ ?p21.3::22q10 $\rightarrow 22 q 11.2:: 22 q 13.1 \rightarrow 22 q$ ter $)[5],+\operatorname{der}(?)$

$(?$ acro-p $\rightarrow$ ?cen::?cen $\rightarrow$ ?acro-p)[4][cp5]

$45, X,-Y[5], t(1 ; 17)(p 34.3 \sim 35 ; \mathrm{q} 21)[4], t(2 ; 10)(\mathrm{p} 24 ; \mathrm{q} 25.3 \sim 26.1)[5], \operatorname{der}(3) \mathrm{t}(1 ; 3)(\mathrm{q} 12 \sim 21 ; \mathrm{q} 24)$

[2] or $\operatorname{der}(3)(3 \mathrm{pter} \rightarrow 3 \mathrm{q} 24:)[3],+\operatorname{der}(5)(: 5 \mathrm{q} 10 \rightarrow 5 \mathrm{qter})[5], \operatorname{der}(5 ; 6)(5 \mathrm{pter} \rightarrow 5 \mathrm{p} 10:: 6 \mathrm{q} 10 \rightarrow 6 \mathrm{q} 15:)$

[5],inv(7)(p11.2p22)[5],

PB2B

$\operatorname{der}(8)(? 9 ? \rightarrow ? 9 ?:: 8 \mathrm{p} 22 \rightarrow 8 \mathrm{qter})[5], \operatorname{der}(9)(8 \mathrm{pter} \rightarrow 8 \mathrm{p} 22:: 9 \mathrm{p} 24 \rightarrow 9 \mathrm{q} 22:: 3 \mathrm{q} 23 \rightarrow 3 \mathrm{qter})[5]$, der(10) $\mathrm{t}(6 ; 10)(? ; \mathrm{q} 10)[5], \operatorname{del}(11)(\mathrm{p} 15.2 \sim 15.4)[4], \operatorname{der}(12)(12 \mathrm{pter} \rightarrow 12 \mathrm{q} 11:: 12 \mathrm{q} 13 \rightarrow 12 \mathrm{qter})[5], \operatorname{der}(12)$

$(12 \mathrm{pter} \rightarrow 12 \mathrm{q} 13:: 12 \mathrm{q} 13 \rightarrow 12 \mathrm{q} 11:: 12 \mathrm{q} 13 \rightarrow 12 \mathrm{qter})[4], \operatorname{der}(15) \mathrm{t}(2 ; 15)(\mathrm{p} 11.2 ; \mathrm{p} 12)$ [5],del(16)

$(q 11.2 q 22)[5], \operatorname{der}(18) t(6 ; 18)(p 12 ; p 11.3)[5], \operatorname{der}(18) t(12 ; 18)(? ; q 22)[4], \operatorname{der}(20)(: 20 ? q 13.1 \rightarrow 20$

?q13.1::20p13 $\rightarrow 20 q$ ?13.1::20q?13.1 $\rightarrow 20 q \operatorname{ter})[5], \operatorname{der}(21) t(9 ; 21)(q 22 ; p 12)[5], \operatorname{der}(22) t(14 ; 22)$ $(\mathrm{q} 22 ; \mathrm{q} 10)[5][\mathrm{cp} 5]$

44 45,X,-Y [5],?del(2)(q3?2q3?3)[5], $\operatorname{der}(3) \mathrm{t}(2 ; 3)(\mathrm{p} ? 14 \sim 21 ; \mathrm{p} 25 \sim 26)[5], \operatorname{der}(3)$

$(3 p t e r \rightarrow 3 p 10:: 12 q 21 \rightarrow 12 q$ ter $)[4]$, der(4) (4pter $\rightarrow 4 q 21:: 4 q ? \rightarrow 4 q ?:: 4 q 21 \rightarrow 4 q 31:: 4 q ? \rightarrow 4 q ?:: 4 q 3$

$\mathrm{HH}$

$1 \rightarrow 4 \mathrm{q} 3$ ?3::1p35 36.1 $\rightarrow 1 \mathrm{pter})[5], \operatorname{der}(5)(10 \mathrm{qter} \rightarrow 10 \mathrm{q} 24:: 9 \mathrm{q} 34 \rightarrow 9 \mathrm{q} 13:: 5 \mathrm{p} 15 \rightarrow 5 \mathrm{qter})[5], \mathrm{t}(6 ; 14)$

$(q 23 \sim 24 ;$ q23 24)[5],+8 [5], der(9)(9pter $\rightarrow 9 p 10:: ?$ acro-p)[5], der(10)(10pter $\rightarrow 10 q 24:)[5], \operatorname{der}(12)$

$(12 \mathrm{pter} \rightarrow 12 \mathrm{q} 21:: 3 \mathrm{q} 11.2 \rightarrow 3 q \operatorname{ter})[5], \operatorname{der}(14)(:: 14 \mathrm{q} 13 \rightarrow 14 \mathrm{q} 10:: 14 \mathrm{q} 13 \rightarrow 14 \mathrm{qter})[5],-15$ [5], der(17) $\mathrm{t}(? 11 ; 17)(\mathrm{q} 23 ; \mathrm{q} 25)[5], \operatorname{der}(18) \mathrm{t}(3 ; 18)(\mathrm{q} 24 ; \mathrm{q} 22)[5][\mathrm{cp} 5]$

79 81<4n>,X or XX, $+\operatorname{der}(X)(X p t e r \rightarrow X q 23 \sim 24:)[2]$ or $\operatorname{der}(X)(X p t e r \rightarrow X q 23 \sim 24:)[1]$ or $\operatorname{der}(X ; 20)(p 10 ; q 10)[2],-X[5],-X[5],+1$ [5],der(1)(3pter $\rightarrow 3 p 21:: ? \rightarrow ?:: 3 p 21 \rightarrow 3 p 13 \sim 14:: 1 p 31 \rightarrow 1$ $\mathrm{q} 42:: 8 \mathrm{p} 21 \rightarrow 8 \mathrm{pter})[5]$, der(1)(6qter $\rightarrow 6 \mathrm{q} 23:: 1 \mathrm{p} 32 \sim 34 \rightarrow 1 \mathrm{qter})[5]$,

psu dic(1;16)(16pter $\rightarrow 16 \mathrm{q} 24:: 1 \mathrm{q} 22 \sim 25 \rightarrow 1 \mathrm{q} 10:: 1 \mathrm{q} 10 \rightarrow 1 \mathrm{qter})[5], \mathrm{t}(1 ; 11 ; 8)(\mathrm{q} 42 ; \mathrm{q} 23 ; \mathrm{p} 21)$

[5], der(3)t(3;6)(q12 13;?)[5], der(3;10)(q10;q10)[2], der(4)t(4;20)(q33;?q13.1)[5], ?inv(4)

$(\mathrm{q} 33 \mathrm{q} 35)[5], p s u \operatorname{dic}(4 ; 21)(\mathrm{q} 10 ; \mathrm{p} 12 \sim 13)[5], \operatorname{der}(5)(5 \mathrm{pter} \rightarrow 5 \mathrm{p} 10:: 5 \mathrm{q} 35 \rightarrow 5 \mathrm{q} 31:: 1 ? \rightarrow 1 ?:: 7$

$? \rightarrow 7 ?:: 5 \mathrm{q} 35 \rightarrow 5 \mathrm{q} 31:)[4], \operatorname{der}(6)(6 \mathrm{pter} \rightarrow 6 \mathrm{p} 21.3:: 6 \mathrm{p} 21.1 \rightarrow 6 \mathrm{q} 23 \sim 24:: 1 \mathrm{p} 34 \rightarrow 1 \mathrm{pter}) \times 2$ [5],

$\mathrm{t}(6 ; 11)(\mathrm{q} 16 \sim 21 ; \mathrm{q} 21 \sim 22)[5],-7$ [5],der(7)t(7;20)(q22;p11.1 11.2)[3],-8 [5],ins(8;18)(q11.2;?)

SZ4

[2],der(9)t(9;14)(p13 22;q13)x2 [5], der(10)(10pter $\rightarrow 10 \mathrm{q} 24:) \times 1$ [2] or x2 [3], der(10;17) $(17$ pter $\rightarrow 17$ p10::10q10 $\rightarrow 10 q 24:)[2], \operatorname{der}(11)(: 14 q ? 32 \rightarrow 14 q ? 24:: 11 p 15 \rightarrow 11 q 21 \sim 22:)[5],-12$ [5],-

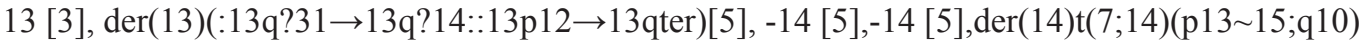
[5], der(15)(10qter $\rightarrow 10 q 24:: 15 \mathrm{p} 12 \rightarrow 15 q \operatorname{ter})[5], \operatorname{del}(16)(\mathrm{q} 11.1)[3], \operatorname{der}(17)(17 \mathrm{qter} \rightarrow 17 \mathrm{q} 10:: 17 \mathrm{q}$ $10 \rightarrow 17 q 25:: ? 3$ ?q13.3 $\rightarrow$ ?3q21:)[2] or $\operatorname{der}(17)(17$ pter $\rightarrow 17 q 25:: 3 ? q 13.3 \rightarrow 3 q 26:: 13 q 31 \rightarrow 13 q$ ter $)$ [3], i(17)(q10)[3],+der(18)(acro-p::18? $\rightarrow 18 ?:: 7 q 22 \rightarrow 7 q \operatorname{ter})[3], \operatorname{der}(18)(8 \mathrm{qter} \rightarrow 8 \mathrm{q} 11.2:: 18 ? \mathrm{p} 11$ $.3 \rightarrow 18$ ?q12::Xq2?8 $\rightarrow$ Xq2?3 2?4::3q13.2 13.3 $\rightarrow 3 q$ ter)[3], der(18)t(8;18)(q11.2;p11.3)[5], -19 [5], der(19)t(7;19)(p11;q13.4)[4], +21 [5],der(21)t(9;21)(p22;q22)x2 [5],-22 [5], +der(?)(acro$\mathrm{p}:: 8 ? \mathrm{q} 13 \rightarrow 8 ? \mathrm{q} 22:)[5][\mathrm{cp} 5]$

(Continued) 
77 80<3n $>, X X[2]$ or $\mathrm{t}(\mathrm{X} ; \mathrm{X})(\mathrm{p} 22.2 ; \mathrm{p} 22.3)[2],-? \mathrm{X}[5],+\mathrm{psu} \operatorname{dic}(1 ; 16)(16 \mathrm{pter} \rightarrow 16 \mathrm{q} 24:: 1 \mathrm{q} 22 \sim 25$ $\rightarrow 1 \mathrm{q} 10:: 1 \mathrm{q} 10 \rightarrow 1 \mathrm{qter})[5], \operatorname{der}(1)(3 \mathrm{pter} \rightarrow 3 \mathrm{p} 21:: ? \rightarrow ?:: 3 \mathrm{p} 21 \rightarrow 3 \mathrm{p} 13 \sim 14:: 1 \mathrm{p} 31 \rightarrow 1 \mathrm{qter})[5], \operatorname{der}(1)$ $(1 \mathrm{pter} \rightarrow 1 \mathrm{q} 42:: 8 \mathrm{p} 21 \rightarrow 8$ pter $)[2]$ or $\mathrm{t}(1 ; 11 ; 8)(\mathrm{q} 42 ; \mathrm{q} 23 ; \mathrm{p} 21)[2],+2[4],+\operatorname{der}(3) \mathrm{t}(3 ; 6)(\mathrm{q} 12 \sim 13 ; ?)$

[5],+der(4)t(4;7)(q23 27;q22)[2] or der(4)t(4;7)(q23 27;q22)[2], der(4)t(4;10)(p15;q25) $[3],+\operatorname{der}(5)(5 \mathrm{pter} \rightarrow 5 \mathrm{p} 10:: 5 \mathrm{q} 35 \rightarrow 5 \mathrm{q} 31:: 1 ? \rightarrow 1 ?:: 7 ? \rightarrow 7 ?:: 5 \mathrm{q} 35 \rightarrow 5 \mathrm{q} 31:)[5], \operatorname{der}(6)(6 \mathrm{pter} \rightarrow 6 \mathrm{p} 21$. $3:: 6 \mathrm{p} 21.1 \rightarrow 6 \mathrm{q} 23 \sim 24:: 1 \mathrm{p} 34 \rightarrow 1 \mathrm{pter})[5], \operatorname{der}(6)(6 \mathrm{pter} \rightarrow 6 \mathrm{p} 21.3:: 6 \mathrm{p} 21.1 \rightarrow 6 \mathrm{p} 10:: 7 \mathrm{p} 13 \rightarrow 7 \mathrm{pter})[2]$,

Sez4 $\mathrm{t}(6 ; 11)(\mathrm{q} 16 \sim 21 ; \mathrm{q} 21 \sim 22)[5],-7$ [3],i(7)(q10)[2],der(8)t(8;11)(p21;q23)[2], +del(9)(q12)[5],der(9) $\mathrm{t}(9 ; 14)(\mathrm{p} 13 \sim 22 ; \mathrm{q} 13) \mathrm{x} 2[5],+10[2]$ or $+\operatorname{der}(10) \mathrm{t}(4 ; 10)(\mathrm{q} 28 ; \mathrm{q} 25)[3], \operatorname{der}(10)(10 \mathrm{pter} \rightarrow 10 \mathrm{q} 24:) \times 2$ [5], $+\operatorname{der}(11)(: 14 \mathrm{q} ? 32 \rightarrow 14 \mathrm{q} ? 24:: 11 \mathrm{p} 15 \rightarrow 11 \mathrm{q} 21 \sim 22:)[3]$ or der(11)(:14q?32 $\rightarrow 14 \mathrm{q} ? 24:: 11 \mathrm{p} 15 \rightarrow 1$ 1q21 22:)[1], der(13)(:13q?31 $\rightarrow 13 q ? 14:: 13 p 12 \rightarrow 13 q$ ter)[3],

-14 [5],der(15)(10qter $\rightarrow 10 \mathrm{q} 24:: 15 \mathrm{p} 12 \rightarrow 15 \mathrm{qter})[5], \operatorname{del}(16)(\mathrm{q} 11.1)[5],+\mathrm{i}(17)(\mathrm{q} 10)[4]$ or i(17) (q10)[1], $\operatorname{der}(18) \mathrm{t}(8 ; 18)(\mathrm{q} 11.2 ; \mathrm{p} 11.3) \times 2$ [5], $\operatorname{der}(19) \mathrm{t}(7 ; 19)(\mathrm{p} 11 ; \mathrm{q} 13.4)[5],+20[5],+\operatorname{der}(21) \mathrm{t}(9 ; 21)$ $(\mathrm{p} 22 ; \mathrm{q} 22) \times 2$ [5],+der(?)(acro-p::8?q13 $\rightarrow$ 8?q22:)[5][cp5]

64 71<3n>,X,-X [5],der(X;16)(q10;p10)[5], $+\operatorname{der}(1) \mathrm{t}(1 ; 2)(\mathrm{p} 10 ; ?) \mathrm{x} 1$ [1] or x2 [3], $\operatorname{der}(1)$ $(: 1 \mathrm{q} 21 \rightarrow 1 \mathrm{p} 36.1:: 1 \mathrm{q} 21 \rightarrow 1 \mathrm{qter})[5], \operatorname{der}(1)(12 \mathrm{qter} \rightarrow 12 \mathrm{q} 21 \sim 23:: 1 \mathrm{p} 21 \rightarrow 1 \mathrm{q} 21:)[5], \mathrm{i}(1)(\mathrm{q} 10)[5]$, $+\operatorname{der}(2 ; 19)(6 \mathrm{qter} \rightarrow 6 \mathrm{q} 22:: 2 ? \rightarrow 2 ?:: 19 \mathrm{q} 10 \rightarrow 19 \mathrm{qter})[3]$ or $\operatorname{der}(2 ; 19)(6 \mathrm{qter} \rightarrow 6 \mathrm{q} 22:: 2 ? \rightarrow 2 ?:: 19 \mathrm{q} 10 \rightarrow$ 19 qter)[2],

$\operatorname{der}(2)(6 \mathrm{qter} \rightarrow 6 \mathrm{q} 22:: 2 ? \rightarrow 2 ?:: 16 \mathrm{q} 11.2 \sim 13 \rightarrow 16 \mathrm{qter})[4], \operatorname{der}(2)(11 \mathrm{qter} \rightarrow 11 \mathrm{q} 14 \sim 21:: 2$ ? $\rightarrow 2$ ?::2?p25 $\rightarrow 2$ ?qter)x1 [2] or x2 [3], $+\operatorname{der}(3 ; 17)(\mathrm{p} 10 ; \mathrm{p} 10)[4]$ or $\operatorname{der}(3 ; 17)(\mathrm{p} 10 ; \mathrm{p} 10)$

[1], $\operatorname{der}(3) \mathrm{t}(\mathrm{X} ; 3)(\mathrm{p} 11.4 \sim 21 ; \mathrm{q} 23 \sim 24)[4], \operatorname{der}(3)(3 \mathrm{pter} \rightarrow 3 \mathrm{q} 12:: 3 ? \rightarrow 3 ?:: ? 11$ or $17 ? \rightarrow ? 11$ or

$\operatorname{SeAx}$ $17 ?:: 3 ? \rightarrow 3 ?:: 9 \mathrm{q} 13 \sim 21 \rightarrow 9 \mathrm{qter})[5]$,

-4 [5],der(4)t(1;4)(p36.1;p16)[4],+der(5)t(5;8)(p13;p22 23)[4],

$+\operatorname{der}(6)(6 \mathrm{pter} \rightarrow 6 \mathrm{q} 10:: 6 ? \rightarrow 6 ?:: 2 \mathrm{q} 22 \sim 23 \rightarrow 2 \mathrm{qter})[4]$ or $\operatorname{der}(6)(6 \mathrm{pter} \rightarrow 6 \mathrm{q} 10:: 6 ? \rightarrow 6 ?:: 2 \mathrm{q} 22 \sim 23 \rightarrow 2$ qter)[1],

$\operatorname{der}(6)(6 \mathrm{pter} \rightarrow 6 \mathrm{q} 22:) \mathrm{x} 1$ [1] or $\mathrm{x} 2$ [4],der(6)(6pter $\rightarrow 6 \mathrm{q} 22:: 2 ? \rightarrow 2 ?:: 6 ? \rightarrow 6 ?:: 16 ? \rightarrow 16 ?)[5], \operatorname{der}(7)$ $(7 \mathrm{pter} \rightarrow 7 \mathrm{q} 32:: 10 \mathrm{q} 22 \rightarrow 10 \mathrm{q} 24:: 5 \mathrm{p} 13 \rightarrow 5$ pter $)[5], \operatorname{der}(8) \mathrm{t}(8 ; 10)(\mathrm{p} 22 \sim 23 ; \mathrm{q} 24) \times 3$ [5], -9 [5], der(10) $\mathrm{t}(5 ; 10)(\mathrm{p} 13 ; \mathrm{q} 24) \mathrm{x} 2$ [5], der(10)(10pter $\rightarrow 10 \mathrm{q} 24:)[4], \operatorname{der}(11) \mathrm{t}(2 ; 11)(? ; \mathrm{q} 14 \sim 21) \mathrm{x} 2$ [5],der(12) $\mathrm{t}(10 ; 12)(? ; \mathrm{p} 12 \sim 13)[5],-13$ [5],der(14)t(12;14)(p12 13;p12)[4],+der(17)t(15;17)(?;p10)[4] or $\operatorname{der}(17) t(15 ; 17)(? ; p 10)[1], \operatorname{der}(17) t(3 ; 17)(q 12 ; q 10) \times 2$ [5], -18 [5],+20 [4][cp5]

71 75<3n $>$,-Y [5],t(X;13)(p11.2 11.4;q14)x1 [1] or x2 [4],+der(2;20)(p10;p10)[5], der(2)(2pte $\mathrm{r} \rightarrow 2 \mathrm{q} 21:: 2$ ?q31 $\rightarrow 2$ ?q33::8q24.1 $\rightarrow 8 \mathrm{qter})[5],+3$ [5], der(3)(3pter $\rightarrow 3 \mathrm{q} 29:: 10 \mathrm{q} 24 \rightarrow 10 \mathrm{qter}) \times 1$ [1] or $\mathrm{x} 2[4],+? 4$ [5],?4 [5], der(4)(4pter $\rightarrow 4 \mathrm{p} ? 14:: 4 ? \mathrm{q} 21 \rightarrow 4$ ?p14::4?q25 $\rightarrow 4$ ?q21::16p?11.1 $\rightarrow 16 \mathrm{p}$ ? $13.3:: 13 q 14 \rightarrow 13 q$ ter $)[5]$, der(4) $(4 \mathrm{pter} \rightarrow 4 \mathrm{p} ? 14:: 4$ ?q21 $\rightarrow 4$ ?p14::4?q25 $\rightarrow 4$ ?q21::16p?11.1 $\rightarrow 16$ $\mathrm{p} ? 13.1:: 6 ? \rightarrow 6 ?:: 11 \mathrm{p} 11.2 \rightarrow 11 \mathrm{pter})[5],-5$ [3],der(5)t(5;8)(?;?)[2], t(5;6)(p10;p10)x2 [5], $+\operatorname{der}(6)$ $(4 \mathrm{qter} \rightarrow 4 \mathrm{q} 21 \sim 24:: 6$ ?p21 $\rightarrow 6$ ?q13::6?q23 $\rightarrow 6 \mathrm{qter}) \times 2$ [5], $+\operatorname{der}(7) \mathrm{t}(7 ; 8)(\mathrm{q} 11.2 ; \mathrm{q} 24.1)[5], \operatorname{der}(7)$ $(10 ? \rightarrow 10 ?:: 7 \mathrm{p} 14 \sim 15 \rightarrow 7 \mathrm{qter}) \times 2[5]$,

Hut78 $\operatorname{der}(8)(? 5 ? \rightarrow ? 5 ?:: 8 \mathrm{q} 10 \rightarrow 8 \mathrm{q} 22 \sim 24.1:: 5 ? \mathrm{q} 33 \rightarrow 5 ? \mathrm{qter})[2]$ or $\operatorname{der}(8 ; 20)(20 \mathrm{qter} \rightarrow 20 \mathrm{q} 10:: 8 \mathrm{q} 10 \rightarrow 8 \mathrm{q} 2$ $2 \sim 24.1:: 5$ ?q33 $\rightarrow 5$ ?qter)[2],

-9 [5], der(9)(Y? $\rightarrow \mathrm{Y} ?:: 9 \mathrm{p} 21 \sim 22 \rightarrow 9 \mathrm{qter}) \times 2$ [5], $\operatorname{der}(10) \mathrm{t}(7 ; 10)(\mathrm{q} 11.2 ; \mathrm{q} 22.2 \sim 22.3)[5], \operatorname{der}(10)$ $(10 \mathrm{pter} \rightarrow 10 \mathrm{q} 24:)[5]$,

$\operatorname{der}(11)(? 16 ? \rightarrow ? 16 ?:: 11 ? \mathrm{p} 12 \sim 14 \rightarrow 11 \mathrm{p} 10:: 11 \mathrm{q} 21 \rightarrow 11 \mathrm{qter})[3], ? \operatorname{del}(12)(\mathrm{p} 13)[2],-13$ [4],+14

[5],?del(14)(q?11.2q?24)x2 [5],+15 [3], -16 [5], +17 [5],+der(18)t(18;20)(?q11.2;?p11.2)

[2],der(18)t(2;18)(?p22 23;p11.2 11.3)x1 [1] or x2 [4],i(18)(p10)[4], +der(19)t(19;20)

$(\mathrm{q} 13 . ? 3 ; \mathrm{q} 11.2)[5], \operatorname{der}(19) \mathrm{t}(19 ; 20)(\mathrm{q} 13 . ? 3 ; \mathrm{q} 11.2)[5], \operatorname{der}(19 ; 22)(\mathrm{q} 10 ; \mathrm{q} 10) \times 2$ [5],+del(20) $(\mathrm{q} 11.2 \mathrm{q} 13.1)[4], \operatorname{del}(20)(\mathrm{q} 11.2 \mathrm{q} 13.1)[1],+\operatorname{der}(20 ; 21)(20 \mathrm{pter} \rightarrow 20 \mathrm{p} 10:: 21 \mathrm{q} 10 \rightarrow 21 \mathrm{q} 22:: 8 ? \mathrm{q} 24.1 \rightarrow 8$ ?qter)[4], der(20)(:9p11 $\rightarrow 9$ p24::20p13 $\rightarrow 20$ qter $) \times 2$ [5], der(20)(20pter $\rightarrow 20 \mathrm{q} 10:: 20 ? \rightarrow 20 ?:: 20 \mathrm{q} 12$ $\rightarrow 20 \mathrm{qter})[2], \operatorname{der}(21)(11 \mathrm{qter} \rightarrow 11 \mathrm{q} 13 \sim 14:: 21 \mathrm{q} 10 \rightarrow 21 \mathrm{qter})[4][\mathrm{cp} 5]$

(Continued) 
60 70<3n>,-Y [5], $\operatorname{der}(\mathrm{X}) \mathrm{t}(\mathrm{X} ; 13)(\mathrm{p} 11.2 \sim 11.4 ; \mathrm{q} 14) \times 2$ [5], $\operatorname{der}(1)(1 \mathrm{pter} \rightarrow 1 \mathrm{q} 31:: 1 ? \rightarrow 1 ?)[5], \operatorname{der}(2)$ $(2 \mathrm{pter} \rightarrow 2 \mathrm{q} 21:: 2$ ?q31 $\rightarrow 2$ ?q33::8q24.1 $\rightarrow 8 \mathrm{qter}) \times 2$ [5], der(3)(3pter $\rightarrow 3 \mathrm{q} 29:: 10 \mathrm{q} 24 \rightarrow 10 \mathrm{qter}) \mathrm{x} 1$ [1] or x2 [4], ?4 [5],?4 [2],der(4)(4pter $\rightarrow 4 \mathrm{q} 22 \sim 24:: ? 6 ? \rightarrow$ ?6?)[2], der(4)(4pter $\rightarrow 4 \mathrm{p} ? 14:: 4$ ?q21 $\rightarrow 4$ ?p1 $4:: 4$ ?q25 $\rightarrow 4$ ?q21::16p?11.1 $\rightarrow 16 \mathrm{p} ? 13.3:: 13 \mathrm{q} 14 \rightarrow 13 \mathrm{qter})[5]$, $\mathrm{t}(5 ; 6)(\mathrm{p} 10 ; \mathrm{p} 10) \mathrm{x} 1$ [1] or $\mathrm{x} 2$ [4],der(5)(5pter $\rightarrow 5 \mathrm{p} 10:: ? \mathrm{acro}-\mathrm{p})[2],+\operatorname{der}(6)(4 \mathrm{qter} \rightarrow 4 \mathrm{q} 21 \sim 24:: 6 ? \mathrm{p} 21$ $\rightarrow 6 ? \mathrm{q} 13:: 6$ ?q23 $\rightarrow 6 \mathrm{qter}) \times 1$ [1] or x2 [4], der(6)(:9p11 $\rightarrow 9 \mathrm{p} 24:: 6 \mathrm{p} 21.3 \rightarrow 6 \mathrm{qter})[5],+\operatorname{der}(7)(7 \mathrm{pter} \rightarrow$ $7 \mathrm{p} 10:: 3 \mathrm{q} 13.2 \rightarrow 3 \mathrm{q} 29:: 10 \mathrm{q} 24 \rightarrow 10 \mathrm{qter})[5]$,

H9 $\operatorname{der}(7)(10 ? \rightarrow 10 ?:: 7 \mathrm{p} 14 \sim 15 \rightarrow 7 \mathrm{qter}) \times 2[5], \operatorname{der}(7)(7 \mathrm{pter} \rightarrow 7 \mathrm{q} 31 \sim 32:: 17 ? \rightarrow 17 ?)[5], \operatorname{der}(8) \mathrm{t}(? 2 ; 8)$ (?;q24.1 24.2)[3], -9 [5],der(9)(Y? $\rightarrow \mathrm{Y} ?:: 9 \mathrm{p} 21 \sim 22 \rightarrow 9 \mathrm{qter}) \times 1$ [2] or $\mathrm{x} 2$ [3], $+\operatorname{der}(10)(10 \mathrm{pter} \rightarrow 10 \mathrm{q} 24:)[4]$ or $\operatorname{der}(10)(10 \mathrm{pter} \rightarrow 10 \mathrm{q} 24:)[1], \operatorname{der}(10)(6 \mathrm{qter} \rightarrow 6 \mathrm{q} 21:: 10 \mathrm{p} 11.2 \rightarrow 10 \mathrm{q}$ $24:: 6 \mathrm{q} 21 \rightarrow 6 \mathrm{qter})[3], \operatorname{der}(10) \mathrm{t}(7 ; 10)(\mathrm{q} 11.2 ; \mathrm{q} 22.2 \sim 22.3) \times 2$ [5], ?del(11)(q?13 14)x2 [5],-13 [5], $\operatorname{der}(13)(10 \mathrm{qter} \rightarrow 10 \mathrm{q} 24 \sim 25:: 2 \mathrm{q} 33 \rightarrow 2 \mathrm{q} 14.3 \sim 21:: 13 \mathrm{q} 10 \rightarrow 13 \mathrm{q} 14:: X \mathrm{Xp11.2} \mathrm{11.4 \rightarrow Xpter})[5], \operatorname{der}(13)$ $\mathrm{t}(\mathrm{X} ; 13)(\mathrm{p} 11.2 \sim 11.4 ; \mathrm{q} 14)[4]$, ?del(14)(q?11.2q?24)[5],-15 [5],-16 [5],+17 [4], +der(18)t(15;18) (q195;q10)[2],i(18)(q10)[4],t(18;18)(p10;p10)[4], +der(19)t(19;20)(q13.?3;q11.2)[5],t(19;20) $(\mathrm{q} 13 . ? 3 ; \mathrm{q} 11.2)[5], \operatorname{der}(19 ; 22)(\mathrm{q} 10 ; \mathrm{q} 10) \times 2[5],+\operatorname{der}(20) \mathrm{t}(6 ; 20)(\mathrm{p} 21.3 ; \mathrm{p} 13)[3]$ or $\operatorname{der}(20) \mathrm{t}(6 ; 20)$ $($ p21.3;p13)[1], der(20)(:9p11 $\rightarrow 9$ p24::20p13 $\rightarrow 20$ qter)[4], der(20)(20pter $\rightarrow 20 q 10:: 20 ? \rightarrow 20 ?:: 20$ $\mathrm{q} 12 \rightarrow 20 \mathrm{qter})[4], \operatorname{der}(21)(11 \mathrm{qter} \rightarrow 11 \mathrm{q} 13 \sim 14:: 21 \mathrm{q} 10 \rightarrow 21 \mathrm{qter})[4][\mathrm{cp} 5]$

MJ

$$
42 \sim 47, X Y, \operatorname{der}(17) \mathrm{t}(2 ; 17)(\mathrm{p} 11.2 ; \mathrm{q} 25)[5][\mathrm{cp} 5]
$$

Hut102 46 or 92,XY or XXYY,der(6)(6pter $\rightarrow 6 \mathrm{q} ? 21:: 6 \mathrm{q} ? 27 \rightarrow 6 \mathrm{q} ? 21:: 6 \mathrm{q} ? 23 \rightarrow 6 \mathrm{q} ? 21:) \times 1$ [3] or x2 [2][cp5]

Importantly, this analysis indicates that chromosomal aberrations (number of abnormalities and their nature) seen in cell lines are representative of karyotype changes that are routinely observed in MF/SS patients.

In summary, $9 \mathrm{MF} / \mathrm{SS}$ cell lines appear to represent six clinical CTLC cases: 1) MyLa, 2) Mac2A/PB2B, 3) $\mathrm{HH}, 4) \mathrm{Hut} 78 / \mathrm{H} 9$, 5) SeAx and 6) Sez4/SZ4, while Hut 102 and MJ genetically differ greatly from classic MF/ SS disease and represent ATLL.

\section{Gene expression changes and clustering of the MF/SS cell lines}

In recent years a number of studies performed analysis of gene expression in MF/SS patients in order to identify novel diagnostic/prognostic markers and to better understand oncogenes and tumor suppressor genes involved in lymphomagenesis [18-20, 43-50]. This work highlighted many genes, whose expression is believed to be important in CTCL (e.g., TOX, GTSF1, LCK, FYB, CCR4, ITK, CD30/TNFRSF8, etc.), which are described in the supplementary tables of our previous reports [18, $20,44,50]$. These genes were time and again validated across multiple studies to play an important role in CTCL pathogenesis. Based on our previous work, we have performed gene expression analysis of the selected 107 selected genes in the 11 patient-derived cell lines and have performed unsupervised clustering analysis based on these expression findings. MJ cells were used as a reference since they showed detectable expression for all 107 genes.
This clustering analysis separated all cell lines into two clusters based on their gene expression profile (Figure 1). Cluster 1 included HH, MyLa, PB2B and Mac2A cells. Importantly, as highlighted in Supplementary Table 1/Supplementary Materials of this report, all these cells were derived from MF patients, albeit most of them had a leukemic stage IV disease. Also, notably, within this cluster Mac2A and PB2B cells clustered together based on the similarities of their gene expression profiles. This is expected, since, as described above, these cells are derived from the same clone that produced different variants of CTCL within the same patient.

Cluster 2, on the other hand, contained all cell lines that were derived from Sézary Syndrome patients (Sez4, SZ4, SeAx, H9 and Hut78) and $H T L V-1^{+}$cells (MJ and Hut 102). Notably, these $H T L V-1^{+}$cells lines clustered together in cluster $2 \mathrm{~B}$ and away from the other SS cells that together formed cluster 2A. Hut78 and H9 clustered together based on their gene expression patterns, as expected. Similarly, Sez4 and SZ4 cells clustered together and they were very similar to the SeAx cells based on the expression of the tested genes.

Hence, this clustering analysis confirms that MyLa, PB2B, Mac2A and HH represent Mycosis Fungoides on a molecular level, while SeAx, Sez4, SZ4, H9 and Hut78 represent Sézary Syndrome. While, MJ and Hut102 $H T L V-1^{+}$cells based on gene expression appear similar to the SS and not leukemic MF variant of CTCL, as highlighted by the karyotype analyses they truly do not represent either. 
Analysis of expression of specific poor vs. favorable markers in patient-derived CTCL cells

Further in-depth analysis of gene expression across the 11 cell lines highlights important downregulation of IFN-y in MF/SS cells (Figure 2A). Also, SERPINB13 favorable prognosis marker was downregulated in all cell lines (Figure 2B), therefore, pointing to the overall advanced disease nature of these cells. Notably, IL-12 is a key cytokine involved in promoting the Th1 immune response. CTCL is known to undergo a switch from the Th1 to Th2 immune response in advanced disease [19]. IL-12A was strongly expressed in MF cell lines (HH, MyLa, PB2B and Mac2A), but not in Sézary cell lines

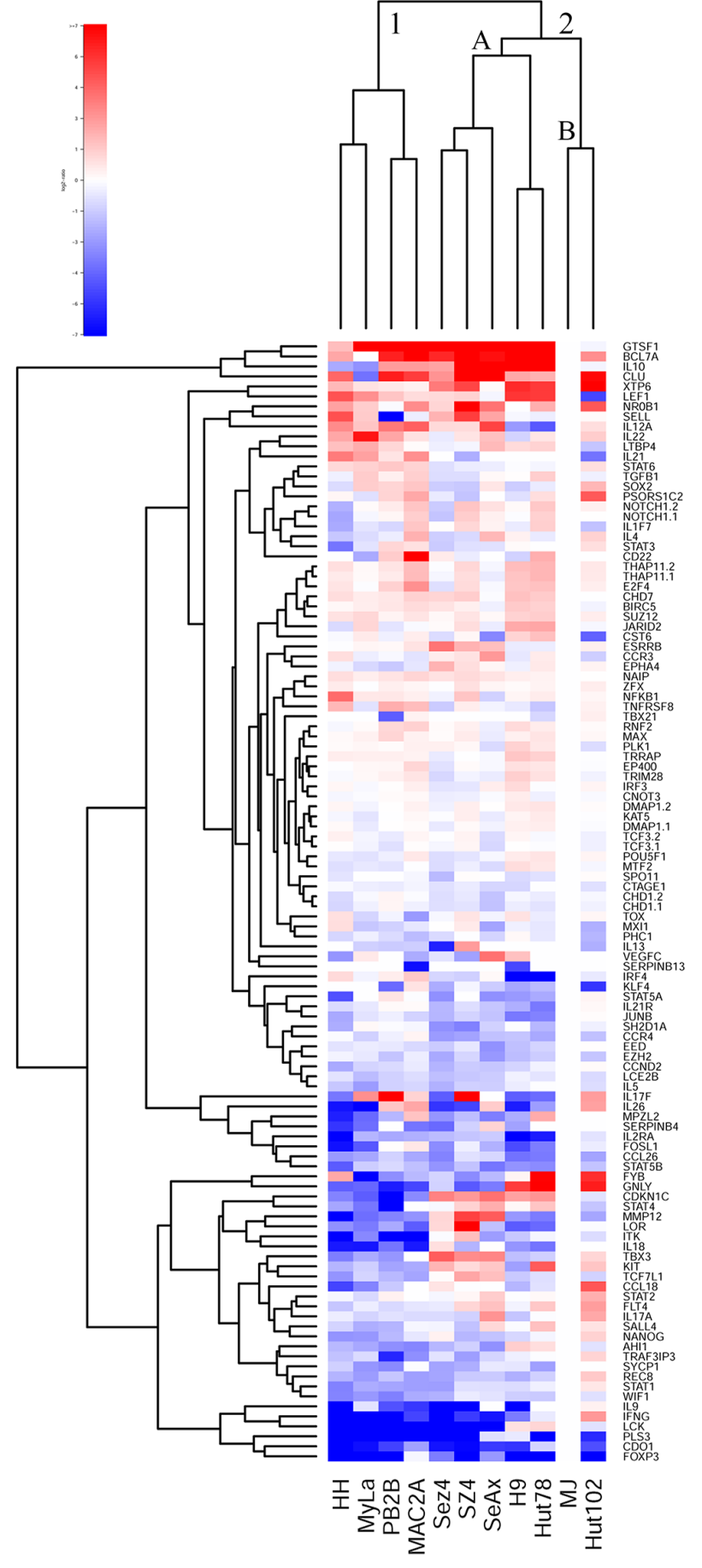

Figure 1: Unsupervised clustering analysis based on RT-PCR expression of 107 select genes in 11 patient-derived cell lines. 
Table 2: TP53 mutation status in patient-derived CTCL cell lines

\begin{tabular}{|c|c|c|c|c|c|c|}
\hline \multirow[t]{3}{*}{ Cell line } & \multicolumn{6}{|c|}{ TP53 Status } \\
\hline & \multicolumn{2}{|c|}{ cDNA } & \multicolumn{2}{|c|}{ Protein } & \multirow[t]{2}{*}{ Codon 72} & \multirow[t]{2}{*}{ MLPA } \\
\hline & Allele 1 & Allele 2 & Allele 1 & Allele 2 & & \\
\hline MyLa & c. $75-80 \mathrm{C}>\mathrm{G}$ & + & + & + & Arg/Arg & Dup x1-11 \\
\hline Mac2A & c. $75-80 \mathrm{C}>\mathrm{G}$ & + & + & + & Arg/Arg & Normal \\
\hline PB2B & c. $75-80 \mathrm{C}>\mathrm{G}$ & + & + & + & Arg/Arg & Normal \\
\hline HH & c. $560-1 \mathrm{G}>\mathrm{A}$ & c. $560-1 \mathrm{G}>\mathrm{A}$ & Splicing affected & Splicing affected & Arg/Arg & Del x1-11/+ \\
\hline $\operatorname{SeAx}$ & c. $733 \mathrm{G}>\mathrm{A}$ & c. $733 \mathrm{G}>\mathrm{A}$ & p.Gly245Ser & p.Gly245Ser & Arg/Arg & Normal \\
\hline SZ4 & c. $75-80 \mathrm{C}>\mathrm{G}$ & c. $75-80 \mathrm{C}>\mathrm{G}$ & + & + & Arg/Arg & Normal \\
\hline Sez4 & c. $75-80 \mathrm{C}>\mathrm{G}$ & c. $75-80 \mathrm{C}>\mathrm{G}$ & + & + & Arg/Arg & Normal \\
\hline \multirow[t]{2}{*}{ Hut78 } & c. $75-80 \mathrm{C}>\mathrm{G}$ & c. $75-80 \mathrm{C}>\mathrm{G}$ & p.Arg196X & p.Arg196X & Arg/Arg & Normal \\
\hline & c. $586 \mathrm{C}>\mathrm{T}$ & c. $586 \mathrm{C}>\mathrm{T}$ & & & & \\
\hline H9 & c. $75-80 \mathrm{C}>\mathrm{G}$ & c. $75-80 \mathrm{C}>\mathrm{G}$ & + & + & Arg/Arg & Normal \\
\hline MJ & c. $75-80 \mathrm{C}>\mathrm{G}$ & + & + & + & Pro/Arg & Normal \\
\hline Hut102 & c. $75-80 \mathrm{C}>\mathrm{G}$ & + & + & + & Arg/Arg & Normal \\
\hline
\end{tabular}

Table 3: Sensitivity (IC50) of the tested cell lines to the 3 commonly used systemic therapies in CTCL

\begin{tabular}{|c|c|c|c|c|c|}
\hline \multicolumn{2}{|l|}{$\bar{A}$} & \multicolumn{2}{|c|}{$\bar{B}$} & \multicolumn{2}{|c|}{$\mathrm{C}$} \\
\hline \multicolumn{2}{|c|}{ Romidepsin } & \multicolumn{2}{|c|}{ Vorinostat } & \multicolumn{2}{|c|}{ Bexarotene } \\
\hline Cells & IC50 $(\mu \mathrm{M})$ & Cells & $\operatorname{IC50}(\mu \mathrm{M})$ & Cells & $\operatorname{IC50}(\mu \mathrm{M})$ \\
\hline Sez4 & 0.14 & Hut78 & 1.43 & MJ & 2.62 \\
\hline $\operatorname{SeAx}$ & 0.14 & H9 & 2.29 & $\operatorname{SeAx}$ & 9.92 \\
\hline H9 & 0.16 & PB2B & 4.90 & Sez4 & 11.35 \\
\hline MyLa & 0.26 & SeAx & 5.79 & PB2B & 13.03 \\
\hline HH & 0.41 & $\mathrm{HH}$ & 29.59 & HH & 13.89 \\
\hline Mac2A & 0.48 & SZ4 & 30.30 & MyLa & 18.23 \\
\hline PB2B & 0.73 & MyLa & 34.38 & H9 & 23.72 \\
\hline Hut78 & 0.77 & MJ & 34.45 & Hut 102 & 28.06 \\
\hline MJ & 2.97 & Sez4 & 37.44 & $\operatorname{Mac} 2 \mathrm{~A}$ & 28.75 \\
\hline SZ4 & 3.03 & $\operatorname{Mac} 2 \mathrm{~A}$ & $>40$ & SZ4 & 28.87 \\
\hline Hut102 & $>4$ & Hut102 & $>40$ & Hut78 & 35.10 \\
\hline
\end{tabular}

(Sez4, SZ4, Hut78 or H9) with a notable exception of SeAx (Figure 2C). None of the cells expressed IL-12B (data not shown) and, hence, are not able to produce a functional IL-12 cytokine. These findings point to the advanced disease state of all tested cells, but suggest that MF cells incompletely lost their ability to express some of the components of the IL-12 machinery. Also, importantly, CD30 expression was detected in all cell lines, but was strongest in $\mathrm{PB} 2 \mathrm{~B}$, Mac2A cells that were derived from a known $\mathrm{CD} 30^{+} \mathrm{MF} / \mathrm{ALCL}$, as well as in $\mathrm{HH}$ cells that were also derived from an advanced $\mathrm{MF}$ patient (Figure 2D).

On the other hand, IL-10 a $\mathrm{T}$ reg cytokine that is known to be expressed in advanced stages was undetectable in MF cells MyLa, HH, Mac2A and PB2B, but was expressed across a panel of Sézary cells, but 
Table 4: T-cell receptor beta and gamma clonality findings for the obtained xenograft tumor tissues

\begin{tabular}{lccccc}
\hline \multirow{2}{*}{ Cell line } & \multicolumn{2}{c}{ TCR gamma receptor } & \multicolumn{3}{c}{ TCR beta receptor } \\
\cline { 2 - 6 } & \multicolumn{1}{c}{ Vy-Jp } & Vy-Jy & TCRB-A & TCRB-B & TCRB-C \\
\hline MyLa & --- & +++ & --- & --- & --- \\
PB2B & +++ & -- & --- & --- & --- \\
HH & +++ & +++ & --- & + & --- \\
Hut78 & --- & +++ & --- & --- & +++ \\
H9 & +++ & +++ & --- & -- & +++ \\
Hut102 & --- & +++ & --- & --- & --- \\
MJ & --- & +++ & --- & --- & --- \\
\hline
\end{tabular}

not $H T L V-1^{+}$cells (Figure 2E). Expression for a number of additional poor prognosis markers including ITK, AHI1, TRAF3IP, FYB, KIT, LCK and TBX3 was further upregulated preferentially in Sézary cells (Figures $2 \mathrm{~F}-2 \mathrm{H}$ and Figure 3A-3D). GTSF1 poor prognosis marker cancertestis gene was previously shown to be strongly expressed in MF/SS patients [18, 20, 44, 47]. This gene was strongly expressed in all 9 tested CTCL cell lines and was only weakly expressed in $H T L V-1^{+}$cells.

These combined gene expression findings further corroborate our earlier conclusions and highlight that while all cells lines represent advanced CTCL disease, MyLa, PB2B/Mac2A, and $\mathrm{HH}$ represent Mycosis Fungoides, where $\mathrm{PB} 2 \mathrm{~B}, \mathrm{Mac} 2 \mathrm{~A}$ and $\mathrm{HH}$ represent $\mathrm{CD} 30^{+}$ MF and/or ALCL disease. On the other hand, SeAx, Sez4/ SZ4, Hut78/H9 represent Sézary syndrome. Hut102 and MJ cells show gene expression profile that is similar to Sézary Syndrome, but truly represent a leukemic form of ATLL.

\section{TP53 mutation status in cell lines}

TP53 mutations were previously reported to occur in advanced disease stages and were associated with poor survival in patients [51]. Hence, we performed the sequencing of the TP53 gene and identified that Sézary cells Hut78 and SeAx carry mutations of p53 (Table 2). HH, advanced MF line, had a change that affects the splicing of the gene. The most common codon polymorphism (at $72^{\text {nd }}$ codon) was Arg/Arg. Only MJ cells had a Pro/Arg polymporphism. MLPA analysis demonstrated duplication of the gene in MyLa and $\mathrm{HH}$ cells (Table 2).

Hut78 and its clonally derived variant, $\mathrm{H} 9$, had a nonsense mutation of p53 in exon 6. SeAx cells had a deleterious Gly245Ser mutation in exon 7. HH cells harbor a c560-1G $>$ A mutation, which is predicted to affect splicing in intron 5 and lead to partial loss of function. Many cell lines had a silent c $75-80 \mathrm{C}>\mathrm{G}$ polymorphism in intron 2, which is predicted not to affect gene expression or function (Table 2).

These findings are consistent with the previous reports of TP53 mutations in advanced disease patients. Considering that all 9 CTCL cell lines represent advanced stages of CTCL, it is not surprising that a number of these cells (i.e., Hut78, H9, SeAx and HH) have mutated TP53. Notably, HTLV-1 $1^{+}$MJ and Hut102 cells had wild type TP53.

\section{Testing cell line sensitivities to commonly used medication treatments in CTCL}

Stage IIB-IVB MF patients that were refractory to two or more standard therapies demonstrated overall response rate of $45 \%$ or $55 \%$ with daily doses of bexarotene 300 or $650 \mathrm{mg} / \mathrm{m}^{2}$, respectively [52]. Histone deacetylase inhibitors (HDACs) on the other hand demonstrated partial response in $29.7 \%$ of patients with only 1 complete response for Vorinostat and $36 \%$ response rate including 5 complete responses for Romidepsin [52]. Hence, we wanted to subject our cell lines to these treatments at various concentrations to determine their sensitivities (i.e., IC50) to Romidepsin, Vorinostat and Bexarotene. As demonstrated in Table 3, the 11 cell lines demonstrated different sensitivities to the tested treatments. Interestingly SeAx and PB2B cells were relatively sensitive to all three treatments, Hut78 and $\mathrm{H} 9$ were sensitive to both HDAC inhibitors (i.e., Romidepsin and Vorinostat), while $H T L V-I^{+}$Hut 102 and MJ cells were relatively resistant to the HDAC inhibitors at concentrations $\leq 40 \mu \mathrm{M}$.

\section{Study of patient-derived cells in NOD.Cg- Prkde $^{\text {scid }}$ Il2 rg $^{\text {tm } 1 \mathrm{~W}_{\mathrm{j}} \mathrm{l} / \mathrm{SzJ} \text { mice }}$}

We then wanted to extend our molecular observations and correlate our findings clinically by implanting and growing these cell lines as subcutaneous 
xenograft tumors in NOD.Cg-Prkdc ${ }^{\text {scid }} \mathrm{Il} 2 \mathrm{rg}^{\mathrm{tm} 1 \mathrm{Wjl}} / \mathrm{SzJ}$ (also commonly referred to as NSG strain) mice. Previous reports demonstrated that these mice could serve as a powerful model to study CTCL pathogenesis [53]. As demonstrated in Figure 4A, 8/11 cell lines were able to produce tumors in mice when implanted subcutaneously.

A
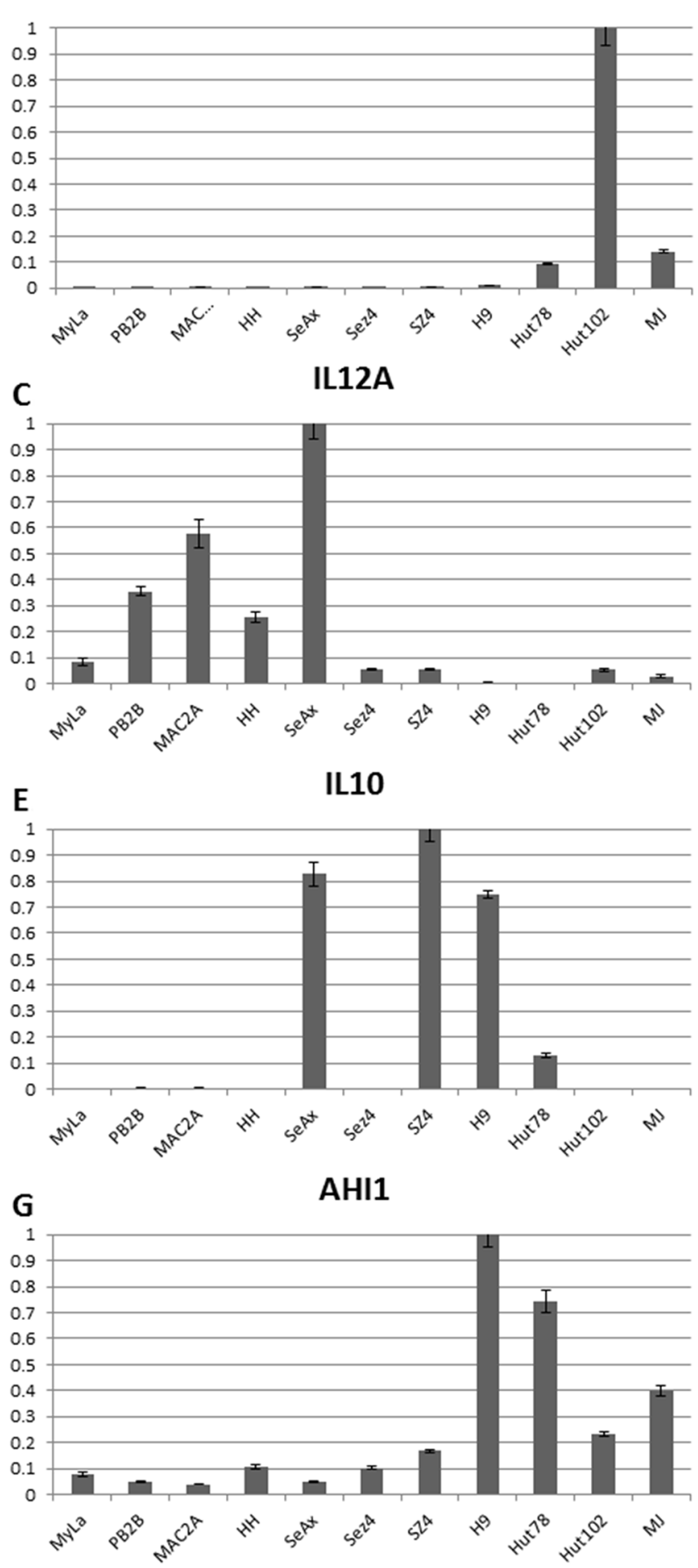

Mac2A, Sez4 and SeAx cells failed to produce tumors on multiple attempts, while PB2B sporadically produced small tumors in $2 / 6$ implantation attempts that were heavily infiltrated by polymorphonuclear leukocytes. Other 8 cell lines reliably produced subcutaneous tumors. Interestingly, MyLa and HH MF lines as well as H9 and Hut78 Sézary

\section{B SERPINB13}
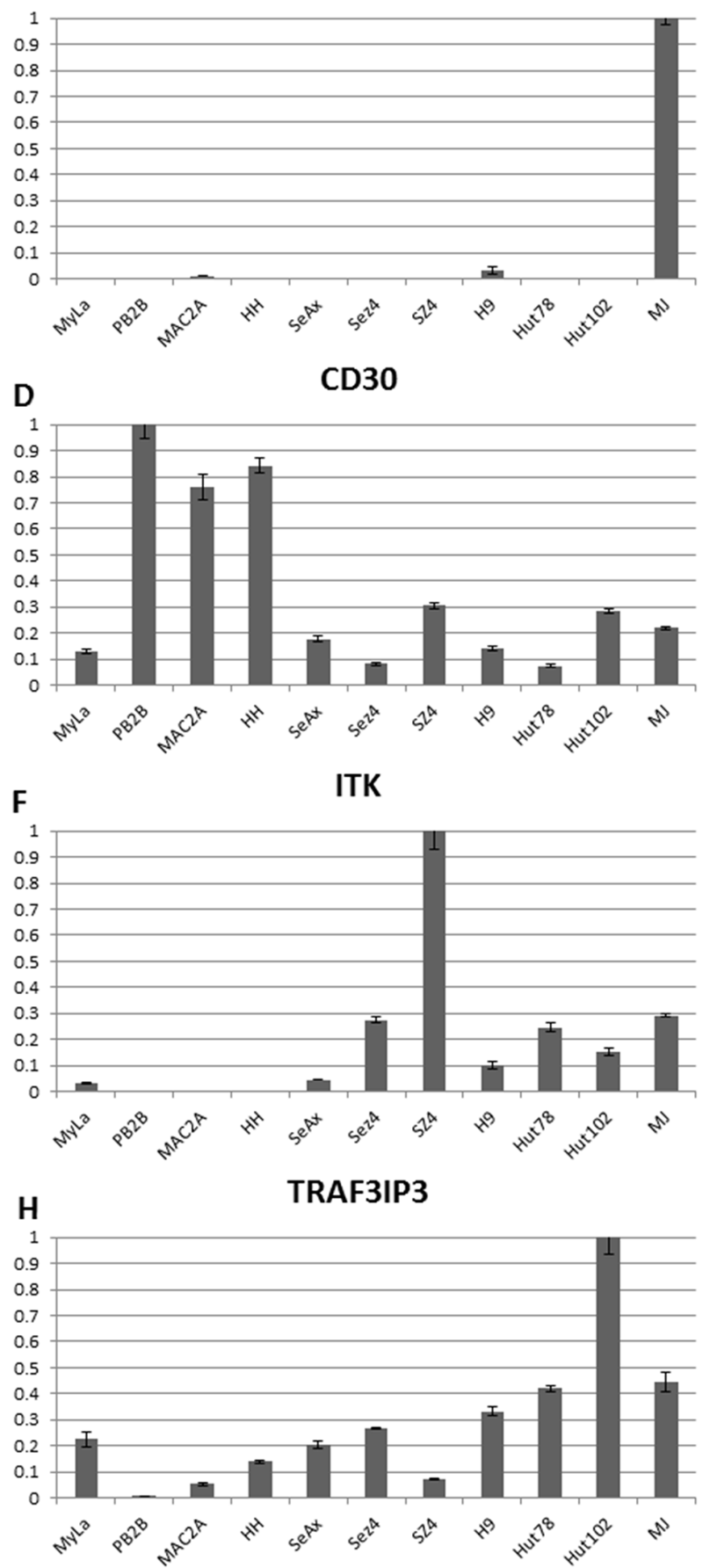

Figure 2: Individual gene expression findings for Th1 cytokines (IFNG, IL-12A), T reg cytokine (IL-10), CD30 and advanced disease/poor prognosis genes (ITK, AHI1 and TRAF3IP3) in 11 patient-derived cell lines. (A-C) CTCL favorable prognosis genes IFNG, IL12A and SERPINB13 mRNA expression. (D-H) Poor prognosis genes CD30, IL-10, ITK, AHI1 and TRAF3IP3 expression. 
cells were most aggressive and produced sizable tumors within 2-4 weeks post implantation. Interestingly, SZ4, but not Sez4 cells also produced smaller tumors and at week 4 these mice had to be euthanized as they were found to be piloerected and barbed. Hut102 and MJ cells too produced measurable tumors, but only 7-9 weeks after the implantation of these cells.

The obtained xenograft tumors were analyzed in a similar way as human CTCL skin biopsy specimens. We performed Hematoxylin and Eosin (H\&E) staining of the tumors, immunophenotyping based on CD3, CD4, CD5, CD7, CD8, CD30 and CD45 RO staining (Figure 4B) and $\mathrm{T}$ cell receptor (TCR) clonality studies using PCR (Table 4). H\&E staining in all cases revealed atypical lymphocytes with many mitotic figures. All cells stained positive for CD4 and only $H T L V-1^{+}$cells had a concomitant positive staining for CD8. CD7 pan T cell marker expression was lost in all tumors, while CD3 and CD5 demonstrated variable expression patterns (Figure 4B). CD5 was expressed in all cells, while CD3 was not expressed in MyLa and PB2B cells and stained only occasional cells in Hut102 tumors. Other cells demonstrated moderate-to-strong CD3 staining (Figure 4B). CD30 was expressed in all cells. Notably PB2B tumors had regional/clonal expression pattern of this genes as islands of cells did not express CD30. CD45RO, a memory $\mathrm{T}$ cell marker, was also strongly expressed in all cell lines, as expected (Figure 4B).

TCR gene rearrangement studies on these xenograft tumors documented that all tissues were derived from clonal events (Table 4). The RT-PCR analysis documented TCR gamma chain was clonal in all cell lines that produced tumors and in addition to that the TCR beta chain was also clonal in HH, Hut78 and H9 cells (Table 4).
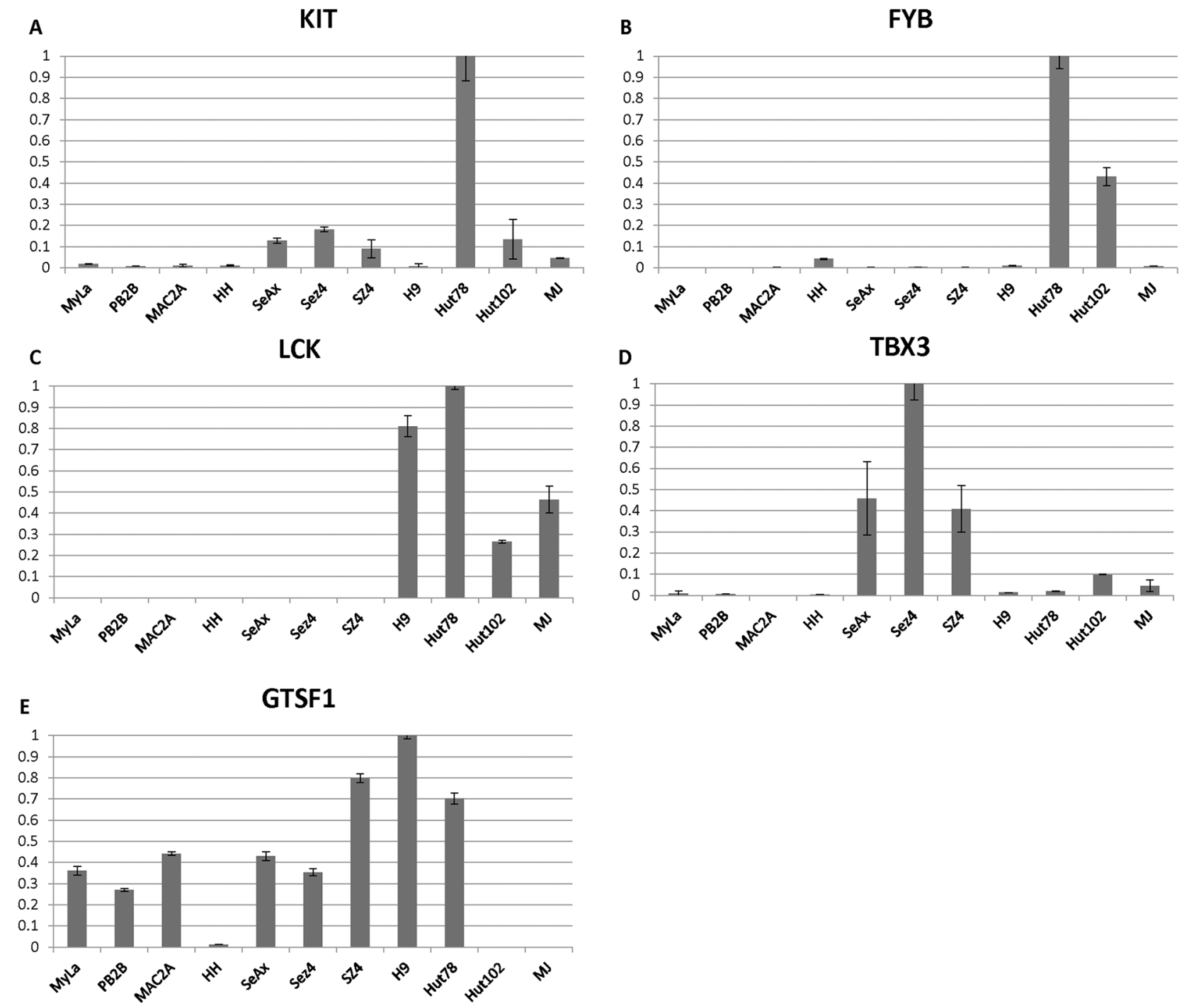

Figure 3: (A-D) Individual gene expression findings for advanced disease/poor prognosis genes (KIT, FYB, LCK, TBX3) and (E) cancer-testis poor prognosis gene GTSF1 in 11 patient-derived cell lines. 
A

Tumor Progression

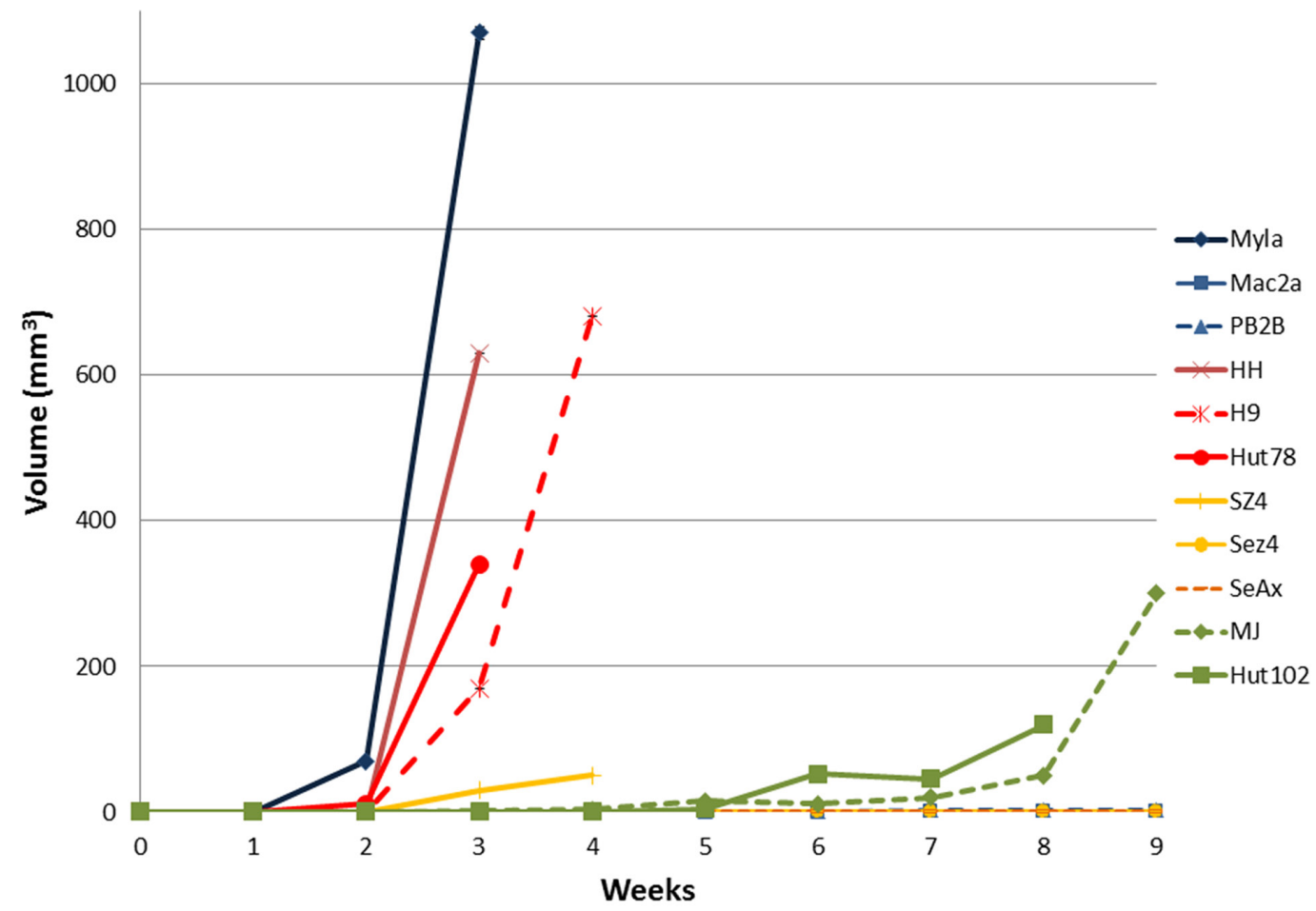

$\mathrm{B}$

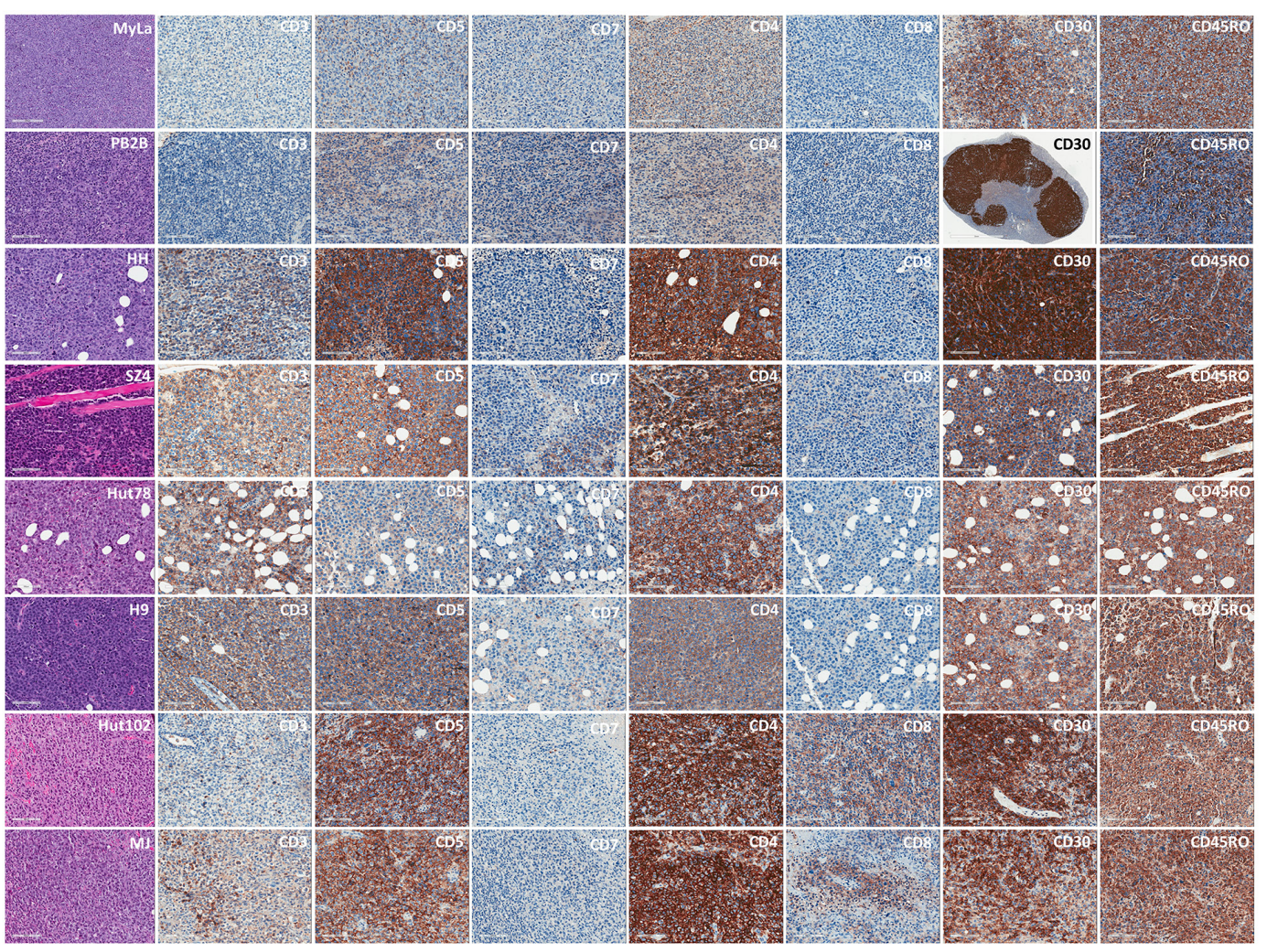

Figure 4: Evaluating the ability of patient-derived CTCL cell lines to produce xenograft tumors in NOD.Cg-Prkdscid

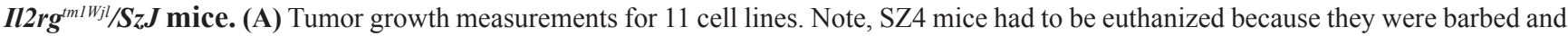
piloerected even though the tumors did not reach $1 \mathrm{~cm}^{3}$ in volume. PB2B cells produced very small tumors that were heavily infiltrated by polymorphonuclear leukocytes. Sez4, SeAx and Mac2A cells did not produce tumors on multiple implantation attempts. (B) Hematoxylin and eosin staining of the obtained tissues and immunohistochemical characterization of these tumors based on pan T-cell marker expression (CD3, CD5, CD7); CD4 vs. CD8 expression; CD30 (advanced disease) and CD45RO (memory T-cell) marker expression. 


\section{DISCUSSION}

While the $H T L V-1$ viruses and their ability to cause ATLL was discovered in 1980's, still today, the controversy ensues whether $H T L V-1$ plays any role in the pathogenesis of MF/SS even in the smallest subset of patients from $H T L V-1$ endemic regions. Furthermore, critical biological differences between $H T L V$-1-driven ATLL and classic MF/SS variants of CTCL remain poorly defined. This study for the first time highlights robust critical molecular differences between $H T L V-1^{+}$patientderived MJ and Hut102 cells that represent ATLL and classic $H T L V-1^{-}$MF/SS cells. Consistent with the welldescribed clinical observation for leukemic ATLL, these cells behave like advanced stage IV MF/SS cancers with respect to gene expression profiling and ability to produce tumors in mice. Furthermore, immunohistochemical analyses of cluster differentiation expression markers and TCR clonality studies in these tumors fall well within the expected range for the advanced MF/SS disease. Also, even though these cells showed lower sensitivity to HDAC inhibitors, their responses to tested medications were comparable to advanced MF/SS cells.

However, most importantly, the karyotype of these cells documented only minimal number of nonspecific chromosomal alterations and these cells were mostly diploid. These findings are consistent with the small numbers of chromosomal abnormalities that were reported in ATLL patients [29, 30]. Also, a 10q24 leukemic chromosomal aberration, common in $\mathrm{MF} / \mathrm{SS}$, was characteristically absent in these cells.

Hence, like horses and zebras $H T L V-1^{+}$leukemia cells and SS/leukemic MF cells look similar despite having a very different genetic composition/origin. This work highlights that the lack of multiple structural abnormalities (including the commonly seen 10q24 aberration) is a important difference between ATLL and classic MF/SS lymphomas that could be used as an important diagnostic test in these patients. In addition, our results indicate that $H T L V-1$ virus is not involved in the pathogenesis of classic MF/SS since, as exemplified by the $\mathrm{MJ} / \mathrm{Hut} 102$ cells, this virus drives a very different pathway of lymphomagenesis that does not lead to an accumulation of a substantial number of chromosomal alterations and, hence, produces a very different cancer on a genetic/chromosomal level. Hence, detection of $H T L V-1^{+}$ serology in any patient should alert a physician that they are dealing with a fundamentally different cancer than the classic MF/SS irrespective of their clinical presentation and disease course.

In this study we also performed a comprehensive comparison and characterization of the available 9 classic MF/SS cell lines. Many researchers in the field use these cells and, unfortunately, often their choice of cells is driven by availability as opposed to understanding what diseases these cell lines truly represent. While some skeptics see limited value in these cells, our work highlights that these cell lines, in fact, do represent typical MF/SS patients. They represent classic karyotypic and gene expression heterogenetiy that is seen in MF/SS cancers. This is especially exemplified by the comparison of karyotype changes that were observed in the 9 studied cell lines when compared to MF/SS patients (Supplementary Table 4). On the molecular level they show similar gene expression patterns that we and others have extensively documented in advanced MF/SS patients [44-47, 50,54]. As seen in a subset of advanced CTCL patients, a number of these cells carry deleterious TP53 gene mutations. They also show heterogeneity of clinical responsiveness to Bexarotene and HDAC inhibitors that is commonly observed in advanced $\mathrm{MF} / \mathrm{SS}$ disease. Importantly, a number of these cells are aggressive enough to produce tumors in NSG mice and these tumors show cluster differentiation marker staining results that are typically seen in classic MF/SS tumors.

We wish to highlight one important limitation in relation to these and other immortalized cancer cell lines. While the presented findings appear to be robust, it is always important to consider that molecular changes can differ in cell lines based on their passage number and culturing conditions.

In this work we further clarified that Sez4 and SZ4 genetically represent the same cell line. We also confirmed that the same malignant clone caused skin lesions in the patient that gave rise to Mac2A and PB2B cells. We validated that $\mathrm{H} 9$ and Hut78 cells represent the same clinical case/event, as expected. Importantly, based on our combined results presented in this paper, these 9 cell lines are only suitable to study advanced MF/SS disease stages. None of these cell lines represent early stage ( $\leq$ IIA) mycosis fungoides. Notably, MyLa represent advanced skin MF, Mac2A/PB2B represent advanced skin $\mathrm{CD} 30^{+} \mathrm{MF} / \mathrm{ALCL}$, while $\mathrm{HH}$ represent leukemic $\mathrm{CD} 30^{+}$ MF. SeAx, Sez4/SZ4 and Hut78/H9 represent true Sézary Syndrome. Hence, based on this study, researchers should use appropriate cell lines in their clinical/translational investigations.

In conclusion, this work highlights key genetic/ biologic similarities and differences between HTLV$1^{+}$and $H T L V-1^{-}$CTCL variants and provides extensive characterization for these 11 cell lines and places them in the context of the clinical spectrum for CTCL disease.

\section{MATERIALS AND METHODS}

\section{Cell lines and culture/treatment conditions}

HH, H9, Hut78, MJ and Hut102 patient-derived CTCL cell lines were previously described $[55,56]$ and were purchased from the American Tissue Culture Collection (ATCC). H9 is a clonal derivative of Hut78 cell line [57]. MyLa, PB2B, Mac2A, SZ4, SeAx, Sez4 were a generous gift from professors K. Kaltoft and N. Ødum 
(Copenhagen, Denmark) and were initially described elsewhere [31, 58-61]. Detailed summary of cell lines is provided in Supplementary Table 1. MJ, Hut78 cells were serially passaged in IMDM media (Invitrogen) containing $20 \%$ and $10 \%$ fetal bovine serum, respectively (FBS) (Invitrogen). HH, H9, Hut102, MyLa, Mac2A and SZ4 cells were grown in RPMI media containing 10\% FBS. Finally, Sez4 and SeAx cells were grown in RPMI media containing $10 \% \mathrm{FBS}, 5 \mathrm{ng} / \mathrm{mL}$ of recombinant human IL-2 and IL-4 (R\&D Systems, Minneapolis, MN). All cells were grown in $5 \% \mathrm{CO}_{2}, 95 \%$ air humidified incubator at $37^{\circ} \mathrm{C}$.

To inhibit histone deacetylase (HDAC) activity cells were treated with $0-40 \mu \mathrm{M}$ of Suberoylanilide Hydroxamic Acid (SAHA also known as Vorinostat, Santa Cruz, Dallas, $\mathrm{TX}$ ) or $0-4 \mu \mathrm{M}$ Romidepsin (Adooq Bioscience, Irvine CA). Cells were also treated with $0-40 \mu \mathrm{M}$ of Bexarotene (Santa Cruz Biotechnology, Dallas, TX).

\section{Quantitative RT-PCR analysis of gene expression}

mRNA from cell lines was isolated using a Quiagen kit (Valencia, CA) and was converted into cDNA using Bio-Rad iScript cDNA synthesis kit. Gene expression on mRNA level was evaluated using quantitative RT-PCR as previously described [18, 19, 20, 43-45]. We have tested 107 genes that were studied and described in our prior work on CTCL patients [44, 50]. Primer pair sequences for the tested genes and control housekeeping genes are listed in Supplementary Table 5. Primer pairs for Tax, Gag, Pol, Env and $p X$ HTLV-1 genes are also listed in Supplementary Table 5. The expression was standardized using genorm method [62] utilizing $A C T B, S D H A$ and $Y W H A Z$ housekeeping genes. Gene expression in MJ cells was set as 1 fold similarly to the protocol in our previous studies [20,45]. MJ cell line was selected as reference, since all genes showed detectable expression in this line. qRT-PCR relative expression was transformed as base- 2 $\log$ of the ratio against MJ cells, independently for each gene. These log2-ratio data points were hierarchically clustered (euclidian distance, complete linkage) using both genes and cell lines as observation points to obtain two dendrograms. The log2-ratio data matrix is shown as a heatmap where rows (genes) and columns (cell lines) are ordered to match the respective dendrogram. Data and figures generated using the $\mathrm{R}$ project for statistical computing (https://www.r-project.org).

\section{G band and spectral karyotyping, TP53 sequencing and MTT cell survival analyses}

G-band and spectral karyotyping of chromosomes was performed in our laboratory and by The Centre for Applied Genomics, The Hospital for Sick Children (Toronto, ON) as previously described [63].
TP53 sequencing was performed by the Molecular Genetics Laboratory, The Hospital For Sick Children (Toronto, ON) as previously described [64, 65]. MTT assay reagents were obtained from Sigma-Aldrich and were performed as previously described [66]. Briefly, standard curves were generated for each cell line to enable conversion from absorbance to cell number values. To obtain IC50 values, cells were plated in 96 well plates and treated for 24 hours using respective concentrations of SAHA (i.e, Vorinostat), Romidepsin and Bexarotene and percent kill was determined using standard MTT protocol.

\section{Xenograft model of CTCL}

The University of Ottawa Animal Care and Ethics Committee approved all experimental procedures involving the xenograft experiments on the immunodeficient NOD.

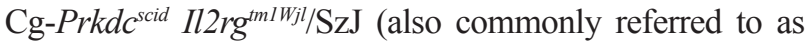
NSG) strain of mice (Jackson Laboratory, Bar Harbor, $\mathrm{ME}$ ). These mice lack mature T cells, B cells or functional NK cells and are deficient in cytokine signaling. The CTCL cell lines Myla, Mac2a, PB2B, HH, H9, Hut78, SZ4, Sez4, SeAx, MJ and Hut102 were harvested individually from tissue culture, pelleted and re-suspended in DPBS (Corning, Manassas, VA). Eight week old female mice were injected subcutaneously (s.c) with $2.5 \times 10^{6}$ cells suspended in a total volume of $200 \mu \mathrm{l}$ of sterile DPBS into the two hind flanks. Mice were housed with enrichment in groups of 4 in a biohazard facility. The condition of the mice was monitored daily for the first 48 hours post injection. Tumor onset and growth was then assessed on a weekly basis by flank palpation within a biosafety cabinet under aseptic conditions. As the tumors progressed, they were measured by slide calipers and recorded over the course of 9 weeks. When tumor progression neared the endpoint volume of $1 \mathrm{~cm}^{3}$, the animals were monitored daily. At experiment termination or wellness endpoint, the mice were euthanized by $\mathrm{CO}_{2}$ followed by cervical dislocation and tumors were excised, measured and weighed.

Tissue processing, Hematoxylin and Eosin (H\&E) staining, immunohistochemical analyses for CD3, CD4, CD5, CD7, CD8, CD30, CD45RO expression and TCR clonality analyses were subsequently performed on the formalin-fixed tumors as per standard clinical protocols in our hospital as previously described [67].

\section{Abbreviations}

adult T-cell leukemia/lymphoma (ATLL); American Tissue Culture Collection (ATCC); body surface area (BSA); cutaneous T-cell lymphomas (CTCL); hematoxylin and eosin (H\&E); histone deacetylase inhibitors (HDACs); human T-cell lymphotropic virus type 1 (HTLV-1); lymphomatoid papulosis (LyP); mycosis fungoides (MF); primary cutaneous anaplastic large cell lymphoma (cALCL); Sézary syndrome (SS); T cell receptor (TCR). 


\section{Author contributions}

EN, DS, IVL designed this study; EN, JG, MT, PT, AW, AKW, JMH, FMG, NO and IVL performed experimental work described in this study; EN, PT, JMH, DS and IVL analyzed the data for this study; EN, AW, NO, DS and IVL wrote the paper; DS and IVL supervised this study.

\section{CONFLICTS OF INTEREST}

The authors declare no competing financial interest.

\section{FUNDING}

This work was supported by the new investigator funding program from the Ottawa Hospital Research Institute to Dr. Litvinov and the Canadian Dermatology Foundation research grants to Dr. Sasseville and Dr. Litvinov, Joan Sealy Trust Cancer Research grant to Dr. Litvinov and the Fonds de la recherche en santé du Québec (FRSQ) research grant to Dr. Sasseville (FRSQ\# 22648) and FRSQ research grants to Dr. Litvinov (\# 34753 and 36769).

\section{REFERENCES}

1. Suzuki R. Pathogenesis and treatment of extranodal natural killer/T-cell lymphoma. Semin Hematol. 2014; 51:42-51.

2. Tsukasaki K, Tobinai K. Human T-cell lymphotropic virus type I-associated adult T-cell leukemia-lymphoma: new directions in clinical research. Clin Cancer Res. 2014; 20:5217-5225.

3. Litvinov IV, Shtreis A, Kobayashi K, Glassman S, Tsang M, Woetmann A, Sasseville D, Odum N, Duvic M. Investigating potential exogenous tumor initiating and promoting factors for cutaneous T-cell lymphomas (CTCL), a rare skin malignancy. Oncoimmunology. 2016; 5:e1175799.

4. Willemze R. (2016). Classification of primary cutaneous lymphomas. In: Corona JAZaR, ed. (https://www.uptodate. $\mathrm{com} /$ contents/classification-of-primary-cutaneouslymphomas:UpToDate).

5. Willemze R, Jaffe ES, Burg G, Cerroni L, Berti E, Swerdlow SH, Ralfkiaer E, Chimenti S, Diaz-Perez JL, Duncan LM, Grange F, Harris NL, Kempf W, et al. WHOEORTC classification for cutaneous lymphomas. Blood. 2005; 105:3768-3785.

6. Goncalves DU, Proietti FA, Ribas JG, Araujo MG, Pinheiro SR, Guedes AC, Carneiro-Proietti AB. Epidemiology, treatment, and prevention of human T-cell leukemia virus type 1-associated diseases. Clin Microbiol Rev. 2010; 23:577-589.

7. Ghazawi FM, Netchiporouk E, Rahme E, Tsang M, Moreau L, Glassman S, Provost N, Gilbert M, Jean
SE, Pehr K, Sasseville D, Litvinov IV. Comprehensive analysis of cutaneous T-cell lymphoma (CTCL) incidence and mortality in Canada reveals changing trends and geographic clustering for this malignancy. Cancer. 2017; 123:3550-3567.

8. Dulmage BO, Feng H, Mirvish E, Geskin L. Black cat in a dark room: the absence of a directly oncogenic virus does not eliminate the role of an infectious agent in cutaneous T-cell lymphoma pathogenesis. Br J Dermatol. 2015; 172:1449-1451.

9. Mirvish ED, Pomerantz RG, Geskin LJ. Infectious agents in cutaneous T-cell lymphoma. J Am Acad Dermatol. 2011; 64:423-431.

10. Olsen E, Vonderheid E, Pimpinelli N, Willemze R, Kim Y, Knobler R, Zackheim H, Duvic M, Estrach T, Lamberg S, Wood G, Dummer R, Ranki A, et al. Revisions to the staging and classification of mycosis fungoides and Sezary syndrome: a proposal of the International Society for Cutaneous Lymphomas (ISCL) and the cutaneous lymphoma task force of the European Organization of Research and Treatment of Cancer (EORTC). Blood. 2007; 110:1713-1722.

11. Jawed SI, Myskowski PL, Horwitz S, Moskowitz A, Querfeld C. Primary cutaneous T-cell lymphoma (mycosis fungoides and Sezary syndrome): part I. Diagnosis: clinical and histopathologic features and new molecular and biologic markers. J Am Acad Dermatol. 2014; 70:205 e201-e216; quiz 221-202.

12. Mangold AR, Thompson AK, Davis MD, Saulite I, Cozzio A, Guenova E, Hodak E, Amitay-Laish I, Pujol RM, Pittelkow MR, Gniadecki R. Early clinical manifestations of Sezary syndrome: a multicenter retrospective cohort study. J Am Acad Dermatol. 2017; 77:719-727.

13. Alsaleh QA, Nanda A, Al-Ajmi H, Al-Sabah H, Elkashlan M, Al-Shemmari S, Demierre MF. Clinicoepidemiological features of mycosis fungoides in Kuwait, 1991-2006. Int J Dermatol. 2010; 49:1393-1398.

14. Sun G, Berthelot C, Li Y, Glass DA 2nd, George D, Pandya A, Kurzrock R, Duvic M. Poor prognosis in non-Caucasian patients with early-onset mycosis fungoides. J Am Acad Dermatol. 2009; 60:231-235.

15. Wilson LD, Hinds GA, Yu JB. Age, race, sex, stage, and incidence of cutaneous lymphoma. Clin Lymphoma Myeloma Leuk. 2012; 12:291-296.

16. Katsuki T, Yamaguchi K, Matsuoka Y, Hinuma Y. Impairment of T-cell control of Epstein-Barr virus infected B-cells in patients with adult T-cell leukemia. AIDS Res. 1986; 2:S125-S130.

17. Yasunaga J, Sakai T, Nosaka K, Etoh K, Tamiya S, Koga S, Mita S, Uchino M, Mitsuya H, Matsuoka M. Impaired production of naive $\mathrm{T}$ lymphocytes in human $\mathrm{T}$-cell leukemia virus type I-infected individuals: its implications in the immunodeficient state. Blood. 2001; 97:3177-3183.

18. Litvinov IV, Netchiporouk E, Cordeiro B, Zargham H, Pehr K, Gilbert M, Zhou Y, Moreau L, Woetmann A, Ødum N, 
Kupper TS, Sasseville D. Ectopic expression of embryonic stem cell and other developmental genes in cutaneous T-cell lymphoma. Oncoimmunology. 2014; 3:e970025.

19. Litvinov IV, Cordeiro B, Fredholm S, Odum N, Zargham H, Huang Y, Zhou Y, Pehr K, Kupper TS, Woetmann A, Sasseville D. Analysis of STAT4 expression in cutaneous T-cell lymphoma (CTCL) patients and patient-derived cell lines. Cell Cycle. 2014; 13:2975-2982.

20. Litvinov IV, Cordeiro B, Huang Y, Zargham H, Pehr K, Dore MA, Gilbert M, Zhou Y, Kupper TS, Sasseville D. Ectopic expression of cancer testis antigens in cutaneous T-cell lymphoma (CTCL) patients. Clin Cancer Res. 2014; 20:3799-3808.

21. Heredia A, Soriano V, Weiss SH, Bravo R, Vallejo A, Denny TN, Epstein JS, Hewlett IK. Development of a multiplex PCR assay for the simultaneous detection and discrimination of HIV-1, HIV-2, HTLV-I and HTLV-II. Clin Diagn Virol. 1996; 7:85-92.

22. Li M, Green PL. Detection and quantitation of HTLV-1 and HTLV-2 mRNA species by real-time RT-PCR. J Virol Methods. 2007; 142:159-168.

23. Wain EM, Mitchell TJ, Russell-Jones R, Whittaker SJ. Fine mapping of chromosome 10q deletions in mycosis fungoides and Sezary syndrome: identification of two discrete regions of deletion at 10q23.33-24.1 and 10q24.3325.1. Genes Chromosomes Cancer. 2005; 42:184-192.

24. van Doorn R, van Kester MS, Dijkman R, Vermeer MH, Mulder AA, Szuhai K, Knijnenburg J, Boer JM, Willemze $\mathrm{R}$, Tensen CP. Oncogenomic analysis of mycosis fungoides reveals major differences with Sezary syndrome. Blood. 2009; 113:127-136.

25. Laharanne E, Oumouhou N, Bonnet F, Carlotti M, Gentil C, Chevret E, Jouary T, Longy M, Vergier B, Beylot-Barry M, Merlio JP. Genome-wide analysis of cutaneous T-cell lymphomas identifies three clinically relevant classes. J Invest Dermatol. 2010; 130:1707-1718.

26. Vermeer MH, van Doorn R, Dijkman R, Mao X, Whittaker S, van Voorst Vader PC, Gerritsen MJ, Geerts ML, Gellrich S, Soderberg O, Leuchowius KJ, Landegren U, Out-Luiting JJ, et al. Novel and highly recurrent chromosomal alterations in Sezary syndrome. Cancer Res. 2008; 68:2689-2698.

27. Caprini E, Cristofoletti C, Arcelli D, Fadda P, Citterich MH, Sampogna F, Magrelli A, Censi F, Torreri P, Frontani M, Scala E, Picchio MC, Temperani P, et al. Identification of key regions and genes important in the pathogenesis of sezary syndrome by combining genomic and expression microarrays. Cancer Res. 2009; 69:8438-8446.

28. Wang L, Ni X, Covington KR, Yang BY, Shiu J, Zhang X, Xi L, Meng Q, Langridge T, Drummond J, Donehower LA, Doddapaneni H, Muzny DM, et al. Genomic profiling of Sezary syndrome identifies alterations of key $\mathrm{T}$ cell signaling and differentiation genes. Nat Genet. 2015; 47:1426-1434.
29. Callens C, Moura IC, Lepelletier Y, Coulon S, Renand A, Dussiot M, Ghez D, Benhamou M, Monteiro RC, Bazarbachi A, Hermine O. Recent advances in adult T-cell leukemia therapy: focus on a new anti-transferrin receptor monoclonal antibody. Leukemia. 2008; 22:42-48.

30. Maruyama K, Fukushima T, Kawamura K, Mochizuki S. Chromosome and gene rearrangements in immortalized human lymphocytes infected with human T-lymphotropic virus type I. Cancer Res. 1990; 50:5697S-5702S.

31. Wasik MA, Seldin DC, Butmarc JR, Gertz R, Marti R, Maslinski W, Kadin ME. Analysis of IL-2, IL-4 and their receptors in clonally-related cell lines derived from a patient with a progressive cutaneous T-cell lymphoproliferative disorder. Leuk Lymphoma. 1996; 23:125-136.

32. Zhang Q, Nowak I, Vonderheid EC, Rook AH, Kadin ME, Nowell PC, Shaw LM, Wasik MA. Activation of Jak/STAT proteins involved in signal transduction pathway mediated by receptor for interleukin 2 in malignant $\mathrm{T}$ lymphocytes derived from cutaneous anaplastic large T-cell lymphoma and Sezary syndrome. Proc Natl Acad Sci U S A. 1996; 93:9148-9153.

33. Barba G, Matteucci C, Girolomoni G, Brandimarte L, Varasano E, Martelli MF, Mecucci C. Comparative genomic hybridization identifies 17q11.2 approximately q12 duplication as an early event in cutaneous T-cell lymphomas. Cancer Genet Cytogenet. 2008; 184:48-51.

34. Fischer TC, Gellrich S, Muche JM, Sherev T, Audring H, Neitzel H, Walden P, Sterry W, Tonnies H. Genomic aberrations and survival in cutaneous T cell lymphomas. J Invest Dermatol. 2004; 122:579-586.

35. Karenko L, Sarna S, Kahkonen M, Ranki A. Chromosomal abnormalities in relation to clinical disease in patients with cutaneous T-cell lymphoma: a 5-year follow-up study. Br J Dermatol. 2003; 148:55-64.

36. Mao X, Lillington D, Scarisbrick JJ, Mitchell T, Czepulkowski B, Russell-Jones R, Young B, Whittaker SJ. Molecular cytogenetic analysis of cutaneous T-cell lymphomas: identification of common genetic alterations in Sezary syndrome and mycosis fungoides. Br J Dermatol. 2002; 147:464-475.

37. Mao X, Lillington DM, Czepulkowski B, RussellJones R, Young BD, Whittaker S. Molecular cytogenetic characterization of Sezary syndrome. Genes Chromosomes Cancer. 2003; 36:250-260.

38. Mao X, McElwaine S. Functional copy number changes in Sezary syndrome: toward an integrated molecular cytogenetic map III. Cancer Genet Cytogenet. 2008; 185:86-94.

39. Prochazkova M, Chevret E, Mainhaguiet G, Sobotka J, Vergier B, Belaud-Rotureau MA, Beylot-Barry M, Merlio JP. Common chromosomal abnormalities in mycosis fungoides transformation. Genes Chromosomes Cancer. 2007; 46:828-838. 
40. Salgado R, Servitje O, Gallardo F, Vermeer MH, OrtizRomero PL, Karpova MB, Zipser MC, Muniesa C, GarciaMuret MP, Estrach T, Salido M, Sanchez-Schmidt J, Herrera $\mathrm{M}$, et al. Oligonucleotide array-CGH identifies genomic subgroups and prognostic markers for tumor stage mycosis fungoides. J Invest Dermatol. 2010; 130:1126-1135.

41. Shapiro PE, Warburton D, Berger CL, Edelson RL. Clonal chromosomal abnormalities in cutaneous T-cell lymphoma. Cancer Genet Cytogenet. 1987; 28:267-276.

42. Thangavelu M, Finn WG, Yelavarthi KK, Roenigk HH Jr, Samuelson E, Peterson L, Kuzel TM, Rosen ST. Recurring structural chromosome abnormalities in peripheral blood lymphocytes of patients with mycosis fungoides/Sezary syndrome. Blood. 1997; 89:3371-3377.

43. Litvinov IV, Zhou Y, Kupper TS, Sasseville D. Loss of BCL7A expression correlates with poor disease prognosis in patients with early-stage cutaneous T-cell lymphoma. Leuk Lymphoma. 2012; 54:653-654.

44. Litvinov IV, Netchiporouk E, Cordeiro B, Dore MA, Moreau L, Pehr K, Gilbert M, Zhou Y, Sasseville D, Kupper TS. The use of transcriptional profiling to improve personalized diagnosis and management of cutaneous T-cell lymphoma (CTCL). Clin Cancer Res. 2015; 21:2820-2829.

45. Litvinov IV, Jones DA, Sasseville D, Kupper TS. Transcriptional profiles predict disease outcome in patients with cutaneous T-cell lymphoma. Clin Cancer Res. 2010; 16:2106-2114.

46. Huang Y, Litvinov IV, Wang Y, Su MW, Tu P, Jiang X, Kupper TS, Dutz JP, Sasseville D, Zhou Y. Thymocyte selection-associated high mobility group box gene (TOX) is aberrantly over-expressed in mycosis fungoides and correlates with poor prognosis. Oncotarget. 2014; 5:44184425. https://doi.org/10.18632/oncotarget.2031.

47. van Kester MS, Borg MK, Zoutman WH, Out-Luiting JJ, Jansen PM, Dreef EJ, Vermeer MH, van Doorn R, Willemze R, Tensen CP. A meta-analysis of gene expression data identifies a molecular signature characteristic for tumor-stage mycosis fungoides. J Invest Dermatol. 2012; 132:2050-2059.

48. Litvinov IV, Kupper TS, Sasseville D. The role of AHI1 and CDKN1C in cutaneous T-cell lymphoma progression. Exp Dermatol. 2012; 21:964-966.

49. Litvinov IV, Pehr K, Sasseville D. Connecting the dots in cutaneous T cell lymphoma (CTCL): STAT5 regulates malignant $\mathrm{T}$ cell proliferation via miR-155. Cell Cycle. 2013; 12:2172-2173.

50. Litvinov IV, Tetzlaff MT, Thibault P, Gangar P, Moreau L, Watters AK, Netchiporouk E, Pehr K, Prieto VG, Rahme E, Provost N, Gilbert M, Sasseville D, Duvic M. Gene expression analysis in cutaneous T-cell lymphomas (CTCL) highlights disease heterogeneity and potential diagnostic and prognostic indicators. Oncoimmunology. 2017; 6:e1306618.
51. Wooler G, Melchior L, Ralfkiaer E, Rahbek Gjerdrum LM, Gniadecki R. TP53 gene status affects survival in advanced mycosis fungoides. Front Med. 2016; 3:51.

52. Jawed SI, Myskowski PL, Horwitz S, Moskowitz A, Querfeld C. Primary cutaneous T-cell lymphoma (mycosis fungoides and Sezary syndrome): part II. Prognosis, management, and future directions. J Am Acad Dermatol. 2014; 70:223 e221-217; quiz 240-222.

53. Huang Y, Su MW, Jiang X, Zhou Y. Evidence of an oncogenic role of aberrant TOX activation in cutaneous T-cell lymphoma. Blood. 2015; 125:1435-1443.

54. Sandoval J, Diaz-Lagares A, Salgado R, Servitje O, Climent F, Ortiz-Romero PL, Perez-Ferriols A, Garcia-Muret MP, Estrach T, Garcia M, Nonell L, Esteller M, Pujol RM, et al. MicroRNA expression profiling and DNA methylation signature for deregulated microRNA in cutaneous T-cell lymphoma. J Invest Dermatol. 2015; 135:1128-1137.

55. Zhang C, Hazarika P, Ni X, Weidner DA, Duvic M. Induction of apoptosis by bexarotene in cutaneous T-cell lymphoma cells: relevance to mechanism of therapeutic action. Clin Cancer Res. 2002; 8:1234-1240.

56. Bunn PA Jr, Foss FM. T-cell lymphoma cell lines (HUT102 and HUT78) established at the National Cancer Institute: history and importance to understanding the biology, clinical features, and therapy of cutaneous T-cell lymphomas (CTCL) and adult T-cell leukemia-lymphomas (ATLL). J Cell Biochem Suppl. 1996; 24:12-23.

57. Chen TR. Karyotypic derivation of H9 cell line expressing human immunodeficiency virus susceptibility. J Natl Cancer Inst. 1992; 84:1922-1926.

58. Abrams JT, Lessin S, Ghosh SK, Ju W, Vonderheid EC, Nowell P, Murphy G, Elfenbein B, DeFreitas E. A clonal CD4-positive T-cell line established from the blood of a patient with Sezary syndrome. J Invest Dermatol. 1991; 96:31-37.

59. Kaltoft K, Bisballe S, Dyrberg T, Boel E, Rasmussen PB, Thestrup-Pedersen K. Establishment of two continuous T-cell strains from a single plaque of a patient with mycosis fungoides. In Vitro Cell Dev Biol. 1992; 28A:161-167.

60. Kaltoft K, Bisballe S, Rasmussen HF, Thestrup-Pedersen K, Thomsen K, Sterry W. A continuous T-cell line from a patient with Sezary syndrome. Arch Dermatol Res. 1987; 279:293-298.

61. Starkebaum G, Loughran TP Jr, Waters CA, Ruscetti FW. Establishment of an IL-2 independent, human T-cell line possessing only the p70 IL-2 receptor. Int J Cancer. 1991; 49:246-253.

62. Vandesompele J, De Preter K, Pattyn F, Poppe B, Van Roy N, De Paepe A, Speleman F. Accurate normalization of real-time quantitative RT-PCR data by geometric averaging of multiple internal control genes. Genome Biol. 2002; 3:RESEARCH0034.

63. Padilla-Nash HM, Wu K, Just H, Ried T, Thestrup-Pedersen K. Spectral karyotyping demonstrates genetically unstable 
skin-homing T lymphocytes in cutaneous T-cell lymphoma. Exp Dermatol. 2007; 16:98-103.

64. Shlien A, Tabori U, Marshall CR, Pienkowska M, Feuk L, Novokmet A, Nanda S, Druker H, Scherer SW, Malkin D. Excessive genomic DNA copy number variation in the Li-Fraumeni cancer predisposition syndrome. Proc Natl Acad Sci U S A. 2008; 105:11264-11269.

65. Tabori U, Baskin B, Shago M, Alon N, Taylor MD, Ray PN, Bouffet E, Malkin D, Hawkins C. Universal poor survival in children with medulloblastoma harboring somatic TP53 mutations. J Clin Oncol. 2010; 28:1345-1350.
66. Litvinov IV, Antony L, Dalrymple SL, Becker R, Cheng L, Isaacs JT. PC3, but not DU145, human prostate cancer cells retain the coregulators required for tumor suppressor ability of androgen receptor. Prostate. 2006; 66:1329-1338.

67. Litvinov IV, Bizet AA, Binamer Y, Jones DA, Sasseville D, Philip A. CD109 release from the cell surface in human keratinocytes regulates TGF-beta receptor expression, TGFbeta signalling and STAT3 activation: relevance to psoriasis. Exp Dermatol. 2011; 20:627-632. 